Int. J. Dev. Biol. 61: 179-193 (2017)

doi: $10.1387 / \mathrm{ijdb} .170030 \mathrm{ye}$

\title{
All in one - integrating cell polarity, meiosis, mitosis and mechanical forces in early oocyte differentiation in vertebrates
}

\author{
YANIV M. ELKOUBY* \\ Department of Developmental Biology and Cancer Research. The Institute for Medical Research Israel-Canada, The \\ Hebrew University Hadassah Medical School, Jerusalem, Israel
}

\begin{abstract}
While the differentiation of oocytes is key for embryonic development, and its investigation is crucial for advancing our understanding of human reproduction and fertility, many fundamental questions in oogenesis have been long standing. However, recent technical advances have led to several breakthroughs mainly in mice and zebrafish. Here I review these recent findings, including regulation and organization of the germline cyst, the mechanistics of chromosomal pairing, establishment of cell polarity, and formation of a universal mRNA-protein (mRNP) granule called the Balbiani body. I discuss common themes in oogenesis from frogs, fish and mouse and compare them to findings from C. elegans and Drosophila. The zebrafish juvenile ovary is an attractive model where these individual processes can be investigated, but also revealing how they are inter-coordinated in oocyte differentiation. A conserved cellular organizer was discovered in the zebrafish oocyte that seems to function at a nexus of oocyte differentiation. This organizer, termed the Meiotic Vegetal Center (MVC), is composed of the oocyte centrosome, and couples meiotic chromosomal pairing with oocyte polarization and Balbiani body formation. The MVC breaks the oocyte symmetry, is regulated by upstream mitotic division in the cyst and nucleates Balbiani body mRNPs prion-like aggregation downstream. These processes can shed new light on broad questions in biology, such as how mitosis contributes to cell polarity, and how prion aggregation which lead to neurodegenerative disease when awry, is regulated in a physiological context. Furthermore, novel cytoskeletal structures can unravel cytoplasmic mechanical functions in chromosomal pairing. Finally, together with recently developed tools, genome editing technology now enables a robust genetic analysis of these fundamental processes in the zebrafish, paving the way for a comprehensive cell and developmental view of vertebrate oogenesis.
\end{abstract}

KEY WORDS: meiosis, centrosome, mRNP granule, Balbiani body, chromosomal bouquet, zebrafish germ cell, ovary

\section{Introduction}

Germ cells undergo dramatic processes during their differentiation. While most cell types are destined to perform as an integral part of a functioning tissue, germ cells give rise to individually functioning gametes. The egg, the end product of oogenesis, is the only animal cell that gives rise to an entire organism. During oogenesis, oocyte precursors and early oocytes are in constant changing interactions with other germ and somatic cells. Early oocyte precursor cells form the germline cyst, a universal cellular organization, where mitotic germ cells divide incompletely and remain connected by cytoplasmic bridges. Within the cyst, the oocyte precursor cells are tightly adjacent to each other, develop in synchrony, and are collectively surrounded by somatic follicle cells. Later in their development, differentiating oocytes that separate from the cyst are being wrapped individually with multiple layers of somatic granulosa follicle cells, a process called folliculogenesis. In parallel to these extreme changes, oocytes switch from mitosis

Abbreviations used in this paper: AV, animal-vegetal; $\mathrm{Bb}$, Balbiani body; $\mathrm{CB}$, cytoplasmic bridge; GSC, germline stem cell; mRNP, mRNA-protein; MVC, meiotic-vegetal center; NE, nuclear envelope; PGC, primordial germ cell.

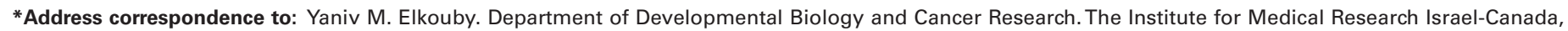
The Hebrew University Hadassah Medical School, Jerusalem 91120, Israel. E-mail: yanive@ekmd.huji.ac.il -Tel: +1-4848-832-3200.
} 
to meiosis, exhibit dramatic nuclear events during early meiosis, and form a universal mRNP granule in the cytoplasm, called the Balibiani body, that polarizes oocytes of most vertebrate species and likely have other functions in others. These processes exhibit fascinating cell biology and offer an exciting platform to address how cell polarity, meiosis, mitosis and mechanical forces are all integrated and coopted in cellular differentiation during development.

Many of the current paradigms in oogenesis come from investigations in Drosophila. However, some aspects of Drosophila oogenesis are not representative of vertebrates. Recently, technical challenges in studying vertebrate oogenesis have been overcome, resulting in several breakthroughs mainly in fish and mice. These advances provide the opportunity to generate a more comprehensive model of vertebrate oogenesis. Here, I discuss these advances, focusing on contributions from the zebrafish, while comparing observations from other models and discussing common themes in mammalian and non-mammalian vertebrate oogenesis.

\section{The zebrafish juvenile ovary - a new model for early oogenesis}

Early stages of oogenesis encompass major processes that are crucial for the formation of a competent oocyte and egg, and subsequently for proper embryonic development (discussed below). Two major examples are the correct execution in meiosis of chromosomal synapse and recombination for the generation of a fit genome of progenies, and the establishment of animal-vegetal polarity that later patterns the embryo and generates its proper body plan. However, while meiotic mechanisms are generally understood, key information on how chromosomes initiate and execute pairing was lacking. In addition, what are the mechanisms that establish cell polarity in the oocyte and their regulation were unknown. Moreover, how cell polarity mechanisms and the meiosis program are coordinated with one another and with the changing cellular organization that underlies early oocyte differentiation has been unknown. This gap results mostly from technical challenges in addressing early oogenesis.

Amorphological analysis of cellular features during development requires a three-dimensional high resolution view. The physical properties and non-synchronous oocytes composition of the adult zebrafish ovary presents several challenges for such an analysis of early developing oocytes. While early differentiating oocytes are very small (8-50 $\mu \mathrm{m}$ in diameter) and transparent, many of the oocytes in the adult ovary are at much later stages, which are very large (200-730 $\mu \mathrm{m})$ and opaque. The entire ovary is thick and lobular. In this setting, it is difficult to identify the small and transparent early oocytes among the larger opaque oocytes. Moreover, the thickness of the adult ovary makes it challenging to obtain uniform penetration of antibodies and vital dyes, a prerequisite for high resolution quantitative imaging techniques. Finally, such a thick sample significantly reduces the quality of image acquisition by confocal microscopy. Early oogenesis in the zebrafish has been, therefore, addressed mainly by immunohistochemistry and in situ hybridization performed on tissue sections (i.e., (Howley \& Ho, 2000; Kosaka et al., 2007; Rodriguez-Mari et al., 2005)), but this analysis lacks three dimensional information. While later stages of oogenesis are better understood in the zebrafish, these limitations resulted in a gap in the understanding of oogenesis earliest stages.

The zebrafish juvenile ovary provides a great platform for a comprehensive investigation of early oogenesis, and filling this gap (Elkouby \& Mullins, 2017; Elkouby et al., 2016). The juvenile ovary is flat and elongated and contains only early differentiating transparent oocytes (Fig. 1A) of similar stages that progress weekly (Elkouby \& Mullins, 2017; Maack \& Segner, 2003). The juvenile ovary therefore offers excellent conditions for staining and confocal imaging techniques (Fig. 1). The abundancy of early oocytes of a desired stage in a given ovary allows for robust analysis of specific stages, fully revealing their intricate developmental dynamics.

In addition to these physical advantages, juvenile ovaries are far more accessible and their investigation allows for a more rapid and powerful statistical analysis. In the mouse, for example, early oogenesis occurs in-utero. The brood size is of only few pups, and only $\sim 50 \%$ of these are female fetuses. The investigation of fetal ovaries is therefore limited to a very small sample size in every experiment. In zebrafish, early oogenesis occurs in the ovary of the juvenile fish, between 3-8 weeks post fertilization. The large zebrafish brood size yields dozens to hundreds juvenile fish per mother.

Moreover, because sex determination, which occurs in fetal gonads in mice, occurs later in zebrafish, juvenile gonads of all fish initiate their development as ovaries, with a potential to continue to develop as ovaries or later transition to testis. The transitioning of ovaries to testis is executed by oocyte apoptosis, loss of expression of female hormones enzymes in somatic cells in the ovary, and the induction of male enzymes expression (Anderson et al., 2012; Dranow et al., 2013; Rodriguez-Mari et al., 2010). However, the initial signal for sex determination is not fully understood, and involves environmental cues in laboratory zebrafish strains, (Dranow et al., 2013; Maack \& Segner, 2003; Rodriguez-Mari etal., 2010). Sex specific SNPs in laboratory strains (Howe et al., 2013), and specific loci that were associated with sex determination in wild type non-laboratory strains (Anderson et al., 2012) suggest genetic regulation in sex determination, but these have yet to be tested functionally. It has been proposed that sex determination in zebrafish is polygenic, and that sex determination associated genes could respond to environmental cues (Anderson et al., 2012). Nevertheless, oocytes in early juvenile ovaries differentiate normally (Dranow et al., 2013; Elkouby \& Mullins, 2017; Elkouby et al., 2016; Maack \& Segner, 2003; Rodriguez-Mari et al., 2010). Therefore, the use of ovaries prior to sex determination takes advantage of the fact that all individuals initially develop as females, making ovaries 2-fold more accessible, with dozens to hundreds of females in every generation, and allowing for larger sample sizes in experiments.

Fulfilling these advantages of the juvenile ovary to their fullest, a toolkit of protocols for the investigation of the juvenile ovary has been generated (Elkouby \& Mullins, 2017). These methods include quantitative microscopy and live time-lapse imaging of whole mount ovaries, ovarian culturing protocol, allowing for the use of pharmacological drugs and expanding the zebrafish genetic experimental repertoire, and a method for isolating stage specific oocytes for biochemical analysis (Fig. 1). In addition, the early stages of oogenesis have been characterized and accurate staging criteria for early oocytes have been established (Elkouby \& Mullins, 2017; Elkouby et al., 2016). Altogether, this toolbox has recently provided an excellent view of early oogenesis processes. 
As I discuss in the next sections, these include insights for the cyst cellular organization and its contributions to differentiation, the discovery of novel cytoskeletal features that may play mechanical roles in the cyst, and the dissection of polarization mechanisms revealing the coupling of oocyte patterning with meiosis by a novel cellular organizer (Elkouby etal., 2016). Thus, the zebrafish juvenile ovary provides a common platform for the investigation of how these cell biological processes are coordinated and integrated in oocyte differentiation.

\section{Keystones in early oocyte differentiation}

\section{From germline stem cells to mitotic oogonial cells}

Primordial germ cells (PGCs) are specified during early embryogenesis and then migrate into the future gonads of the embryo (Paksa \& Raz, 2015). At later stages, PGCs give rise to germline stem cells (GSCs) in the gonads. GSCs generates meiotic oocytes, as shown through genetic lineage tracing in both the fish Medaka and the mouse (Lei \& Spradling, 2013; Nakamura et al., 2010). In zebrafish, actively dividing GSCs that likely generate meiotic oocytes were identified in both the juvenile and adult ovary (Beer \& Draper, 2013). Zebrafish and Medaka GSCs specifically express nanos2 (Beer \& Draper, 2013; Nakamura et al., 2010), and mutant analysis in zebrafish demonstrated that the maintenance of the nanos2+ GSCs population is required for the generation of oocytes and fertility throughout life (Beer \& Draper, 2013). A related gene, nanos3 is dispensable for the establishment of nanos2+ GSCs, but required for their maintenance, and in nanos ${ }^{-\%}$ ovaries the initial pool of nanos2+ GSC gives rise to oocytes in the juvenile ovary, but as the nanos2+ GSCs are not maintained, oocytes are all lost in the adult ovary (Beer \& Draper, 2013; Dranow et al., 2013). However, how GSCs are regulated is unknown. It is not known how they are born from PGCs, and how their proliferation, self-renewal, and generation of subsequent mitotic cells and differentiating oocytes are controlled. In addition, while GSCs were proposed to reside at the surface of the ovary in both Medaka and zebrafish (Beer \& Draper, 2013; Nakamura et al., 2010), their morphological organization in the ovary is unclear and whether they are found in or require a niche is unknown.

GSCs give rise to mitotic oogonia, in a yet unknown mechanism. Mitotic oogonia are the precursor cells of meiotic oocytes, but before oocytes are generated, oogonia go through several cell divisions (Leu \& Draper, 2010). The exact number of cell divisions of the oogonia vary slightly between species. These divisions however, undergo incomplete cytokinesis and abscission between daughter cells is not executed until later stages. Oogonial cells thus remain connected via cytoplasmic bridges (CBs) (Marlow and Mullins, 2008), forming a germline cyst, a universal cellular
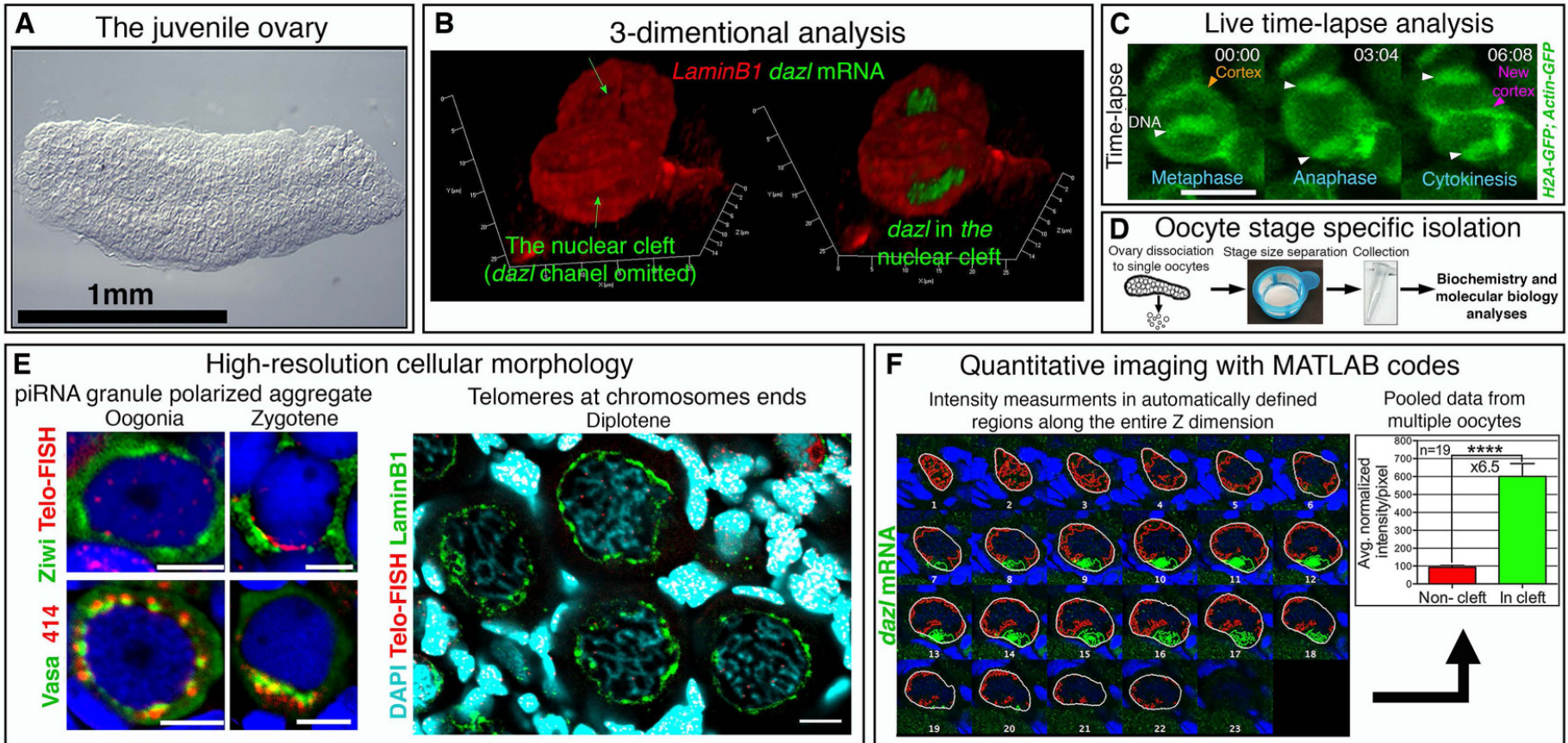

Telomeres at chromosomes ends
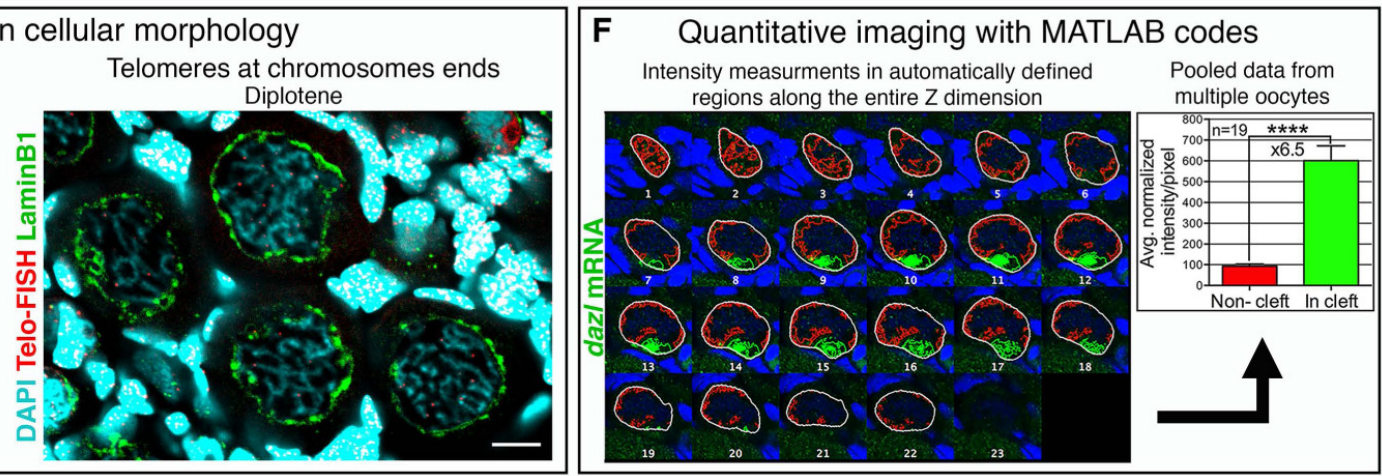

Fig. 1. The experimental system of the juvenile zebrafish ovary. (A) A dissected, fixed and mounted juvenile ovary. Note the small size of the ovary, which is thin and transparent, and so ideal for quantitative microscopy. At these stages, the ovary contains only oogonia, and early oocytes through early diplotene stages $(<60 \mu \mathrm{m})$ in vast numbers, in contrast with the adult ovary that contains many large $(<300 \mu \mathrm{m})$ and opaque oocytes. (B-F) Recently established experimental methods for investigation of the juvenile ovary. (B) A 3-dimensional analysis. Lamin B1 shows the morphology of the nuclear cleft with an aggregating Bb component, the dazl mRNA. (C) Live time-lapse analysis in cultured ovaries. Tracking of oogonial cell division by H2A-GFP (DNA) and Lifeact-GFP (cortical actin). Scale bar, 10 um. (D) Isolation of stage specific oocytes in high developmental resolution for molecular biology and biochemical analysis. Isolated oocytes are separated by size using cellular strainers. (E) Imaging in high resolution morphology. Left: perinuclear piRNA granules undergo polarization during zygotene stages. Scale bar, 5 um. Right: Telomeres are detected at chromosomal ends with the nuclear envelope detected by Lamin B1 at diplotene stages. Scale bar, 20 um. (F) Quantitative imaging used for analysis by automated MATLAB codes. An example of measuring intensities of Bb components (dazl $m R N A$ ) in the nuclear cleft versus non-cleft cytoplasm is shown. Note the combination of fluorescent immunohistochemistry with either RNA fluorescent in situ hybridization (FISH) in (B, F), and with DNA-FISH in (E) (top left and right). Images in (B,E) (left panel) and (F) are modified from Elkouby et al. (2016); images in (A,C) are modified from Elkouby \& Mullins (2017). 
organization of oogonial cells and early meiotic oocytes (Pepling et al., 1999). In the germline cyst germline cells are tightly clustered and collectively engulfed by somatic follicle cells (Elkouby et al., 2016; Leu \& Draper, 2010; Selman et al., 1993). This organization in germline cysts is thought to synchronize the development of individual oocytes (Pepling et al., 1999).

\section{Early differentiation and progression of meiosis}

Ultimately, oogonial cells initiate meiosis, which marks the beginning of oocyte differentiation (stage l oocytes). A major meiosis inducer that has been established in the mouse is retinoic acid (RA) signaling (Anderson et al., 2008; Bowles \& Koopman, 2007; Koubova et al., 2014). While meiosis regulation in the zebrafish ovary is uncharacterized, RA players are interestingly expressed in follicle cells of the zebrafish ovary (Rodriguez-Mari et al., 2013), suggesting that its role in meiotic regulation is likely conserved. The first step in meiosis I, prophase, is prolonged in oocytes. Prophase begins at the onset of meiosis in stage I oocytes (diameter of 10 $\mu \mathrm{m}$ ) in zebrafish and is only completed during oocyte maturation, much later at stage IV of zebrafish oogenesis (diameter of $>300$ $\mu \mathrm{m})$. During prophase of meiosis I primary events in oocyte differentiation take place, including genetic recombination and cellular polarization.

Genetic recombination between homologous chromosomes, which increases genetic diversity of gametes, is a hallmark of meiosis I. Preceding homologous recombination, chromosomes need to first find and pair with their homolog. The physical connection of homologous chromosomes progresses along chromosomal axes and is mediated by protein bridging complexes called synaptonemal complexes. Chromosomal pairing and synapse occurs during leptotene and zygotene stages, the first stages of prophase I. During the leptotene stage, chromosomes attach to the nuclear envelope (NE) via their telomeres. Telomeres then rotate on the NE, tumbling entire chromosomes inside the nucleus, and enabling their homology searches for pairing (Chikashige et al., 2006; Ding et al., 2007; Page \& Hawley, 2003; Saito et al., 2014; Sato et al., 2009; Scherthan, 2001; Trelles-Sticken et al., 2000).

Eventually, the rotating telomeres cluster to one side of the NE and the free looping ends of their chromosomes face the opposite side. This polarized organization is characteristic of the zygotene stage and is called the zygotene chromosomal bouquet. The bouquet is thought to help stabilize chromosomal synapsis (Chikashige et al., 2006; Ding et al., 2007; Page \& Hawley, 2003; Saito et al., 2014; Sato et al., 2009; Scherthan, 2001; Trelles-Sticken et al., 2000). In principle, these rapid chromosomal dynamics are regulated by centrosome-based microtubules in the cytoplasm that connect to the telomeres on the NE via Sun/KASH proteins that span the two membranes of the NE (Chikashige et al., 2006; Ding et al., 2007; Morimoto et al., 2012; Sato et al., 2009). Microtubules in this way are required for chromosomal movements and telomere clustering (Elkouby et al., 2016; Sato et al., 2009; Shibuya, Morimoto, et al., 2014). I discuss the mechanisms and regulation of bouquet formation more comprehensively below (section 5 ).

A second requirement for recombination is the formation of DNA double strand breaks (DSBs) during the leptotene stage (Burgoyne et al., 2009; Saito et al., 2011). Upon establishment of stable synapsis at zygotene, chromosomes recombine at some of the DSB sites during the pachytene stage (Bolcun-Filas et al., 2014; Burgoyne et al., 2009; Lake \& Hawley, 2012; MacQueen
\& Hochwagen, 2011). At pachytene, the clustered telomeres of the bouquet are released and become radially distributed on the NE and then unload back into the nucleus (Elkouby et al., 2016). Oocytes then enter the diplotene stage and meiosis arrests until oocyte maturation late in oogenesis (stage IV). This prolonged diplotene stage is also called dyctate.

Another hallmark of early oocyte is formation of a large mRNP granule, called Balbiani body $(\mathrm{Bb})$, that is associated with oocyte survival in mice and polarizes the oocyte in zebrafish. Importantly, $\mathrm{Bb}$ formation was recently found to be mechanistically coupled with bouquet formation in zebrafish (Elkouby et al., 2016). Later, $\mathrm{Bb}$ formation was linked to bouquet features and at similar stages in insects and mice (Lei \& Spradling, 2016; Tworzydlo, Kisiel, et al., 2016). The theme emerges is of the integration of the meiotic program with other processes in oocyte differentiation. I discus these in section 7.1.

\section{Later differentiation and growth}

In this review, I focus on events of early oogenesis until approximately mid-diplotene of st. I, roughly the equivalent of the mouse primordial-primary follicle stages. During these early stages the oocyte grows from a diameter of $10 \mu \mathrm{m}$ in the oogonia stage to 25 $\mu \mathrm{m}$ at early diplotene in zebrafish (Elkouby et al., 2016). However, during the meiosis arrest in subsequent stages, the zebrafish oocyte grows dramatically, reaching a massive size of $690 \mu \mathrm{m}$ in diameter before maturation and meiosis resumption (Selman et al., 1993), as follows. During stage II (oocyte diameter of 140-340 $\mu \mathrm{m}$ ), oocytes start generating the vitelline envelope and form cortical granules for the later cortical reaction that modifies the vitelline envelope (i.e. the chorion) following egg activation. Oocytes of stage III (oocyte diameter of $340-690 \mu \mathrm{m}$ ) are referred to as the vitellogenesis stage, when vitellogenin (yolk) protein accumulates. Oocytes then resume and complete meiosis I during stage IV (oocyte diameter of 690-730 $\mu \mathrm{m})$, referred to as oocyte maturation, and become a fully mature egg at stage $V$ (oocyte diameter of 730-750 $\mu \mathrm{m}$ ) during ovulation. Stages II-III are equivalent to the stages of follicle development in mammals where the entire follicle grows dramatically, but the oocyte within the follicle also grows significantly (in the mouse for example, from $\sim 20 \mu \mathrm{m}$ to $\sim 80 \mu \mathrm{m}$ in diameter (Griffin et al., 2006). A dramatic growth during these stages is characteristic to oocytes of mammalian and non-mammalian vertebrates.

\section{The germline cyst - the cradle of early oocyte differentiation}

\section{Organization and formation of the germline cyst}

An ovarian germline cyst is defined as oogonia or oocytes that are connected by CBs (cytoplasmic bridges), clustered, and collectively surrounded by somatic follicle cells. A germline nest is a group of clustered oocytes that are collectively surrounded by follicle cells but may not be connected by CBs. In zebrafish, mitotic oogonia cells develop in cysts (Marlow \& Mullins, 2008a), and early meiotic stages likely continue developing in cyst as well (Elkouby et al., 2016). While CBs were not directly demonstrated within clustered oocytes in leptotene and zygotene nests, they were detected in slightly later late zygotene to early pachytene stages (Elkouby et al., 2016). These CBs likely formed in the oogonial cyst when cells last divided mitotically, and persisted through leptotene and zygotene stages. The oogonia, leptotene and zygotene 
clustered organization exhibit three primary characteristics of a germline cyst (Elkouby et al., 2016; Marlow \& Mullins, 2008a):

1. Tightly clustered cells, collectively engulfed by somatic cells. 2. Synchronized development of oocytes. 3. Oocytes are connected by CBs, as detected in oogonia and in late zygotene oocytes. This is consistent with the development of mitotic and early meiotic oocytes in germline cysts in mammals and the fish Medaka (Lei \& Spradling, 2013; Nakamura et al., 2010; Pepling et al., 1999).

The oogonial precursor cells that generate the cyst are born from germline stem cells (GSCs). In the Medaka ovary GSCs were identified by genetic lineage tracing, specifically express nanos2 and were detected in what has been called a 'germinal cradle' (Nakamura et al., 2010). Germinal cradles resided throughout the dorsal surface of the ovary along thread-like cords (Nakamura et al., 2010). In zebrafish, GSC-born oocyte lineages were not directly demonstrated, but there is good evidence for the identification of GSCs that specifically express nanos2 as well (Beer \& Draper, 2013). Interestingly, zebrafish GSCs were also described at the ovary surface where they resided in a lateral anterior-posterior band termed the germinal zone (Beer \& Draper, 2013). A potential niche that regulates these GSCs and how they produce oogonia that will then generate the oogonial and meiotic cyst is not characterized.

Many aspects of oocyte development within the cyst are largely unclear. Importantly, the fundamental cell division pattern that initially forms the cyst is unknown. In the Drosophila prevailing model, the cells in the cyst, called cystoblasts, divide 4 times with all cells in the cyst actively dividing, giving rise to a 16-cell cyst (Greenbaum et al., 2007; Xie, 2013). This pattern is evident in Drosophila by the specialized fusome structure that persists between daughter cells and traces their division plane (Greenbaum et al., 2007; Xie, 2013). Vertebrate oocytes have no fusome and such an analysis has been lacking in zebrafish. The pattern and number of divisions of each cell within the cyst has not been addressed. Since cyst cells develop synchronously, the cyst should contain $2^{n}$ cells ( $n=$ number of cell divisions). In Xenopus cysts contain up to 16 cells (Kloc et al., 2004), whereas in the Medaka and in the mouse, cysts of up to 30 or 32 cells have been identified, suggesting an additional round of cell division can occur in the cyst (Nakamura et al., 2010) (Lei \& Spradling, 2013). Interestingly, mouse cysts exhibit dynamic breakdown into partial cysts that then re-aggregate and form nests of mixed clones (Lei \& Spradling, 2013). Within a clonally mixed nest, each partial cyst develops synchronously, although not in conjunction with other partial cysts of another clonal origin (Lei \& Spradling, 2013). Detection of ring canals, a structure of the $\mathrm{CB}$, in clonal meiotic cysts at E14.5 showed that most cells have two ring canals and few $(\sim 14 \%)$ have three (Lei \& Spradling, 2016). However, a consistent division pattern or cyst morphology could not be determined (Lei \& Spradling, 2016).

Following the last mitosis, the Drosophila cyst always contains 16 cells, with only one differentiating as an oocyte, and the remaining 15 becoming nurse cells (Greenbaum et al., 2007; Matova \& Cooley, 2001; Xie, 2013). Nurse cells produce the vast majority of factors required for the transcriptionally quiescent oocyte. Nurse cells deliver these factors to the oocyte via ring canals that interconnect the cells in the cyst, a process called "cell dumping". In vertebrates nurse cells and cell dumping do not exist, although there is an intriguing recent report in the mouse that cytoplasmic content from one oocyte may be transferred to another, followed by apoptosis of the former (Lei \& Spradling, 2016).
In the vertebrate germline cyst, some oogonial cells undergo apoptosis, while others will enter meiosis and start differentiating. The ratio of cells undergoing apoptosis versus differentiation varies between species. In Xenopusand Medaka, only a few cells around or within the mitotic cyst undergo apoptosis, (Kloc et al., 2004; Nakamura et al., 2010). In contrast, in the mouse only $20 \%$ of the initial cells within cysts ultimately develop into a primordial follicle with the remaining undergoing massive apoptosis, both during cyst stages (Lei \& Spradling, 2013) (Lei \& Spradling, 2016) and at later meiotic checkpoints (Bolcun-Filas et al., 2014; Burgoyne et al., 2009; Lake \& Hawley, 2012; MacQueen \& Hochwagen, 2011). In zebrafish this remains to be addressed, but the lack of obvious massive apoptosis may suggest that zebrafish is more similar to Medaka and Xenopus.

An important contribution of the cyst organization to oocyte differentiation was recently revealed in coordinating oocyte polarization in zebrafish. The oocyte polarization axis was found to be aligned with the last mitotic division plane in the cyst, (Elkouby et al., 2016) (see section "Potential regulation of polarity by cyst mitotic division"). Future analysis of cyst formation is therefore crucial for understanding oocyte differentiation mechanisms.

\section{From cyst to follicle - switching cellular organization}

Ultimately, oocytes leave the cyst and begin the process of folliculogenesis (Pepling, 2012), that is the wrapping of individual oocytes by increasing layers of follicle cells as they continue growing.

In Medaka and mice the latest stage of oocytes detected in a germline cyst is zygotene and the first stage of an individual oocyte that begins folliculogenesis is early diplotene (Nakamura et al., 2010) (Lei \& Spradling, 2016). When exactly the oocyte switches from a cyst to a follicle organization was unclear. This was found to occur in oocytes transitioning from late zygotene to early pachytene stages in zebrafish, with pachytene oocytes beginning folliculogenesis (Elkouby et al., 2016). The timing of transition from a cyst to a follicle organization appears to be conserved to before diplotene stages.

The separation of oocytes from the cyst is not characterized and the separation mechanism and its regulation are unknown. It is not clear whether oocytes separate by the breaking down of the entire cyst and releasing all oocytes at once, or leave the cyst one by one. Single early diplotene oocytes were observed nearby single cysts in Medaka (Nakamura et al., 2010), which could suggest that oocytes may segregate from the cyst one by one. However, these early diplotene oocytes were motile and re-located from being adjacent to one cyst to being adjacent to another (Nakamura et al., 2010), challenging the definitive identification of their source. Cyst breakdown in the mouse is thought to involve robust apoptosis of oocytes (Lei \& Spradling, 2016), but in Medaka only few apoptotic oocyes are detected in the cyst (Nakamura et al., 2010). While these could contribute to oocyte separation, additional regulation is likely. An interesting hypothesis for a cyst separation mechanism comes from the zebrafish. Late zygotene-early pachytene oocytes were always detected at a periphery of a cyst and had long cytoplasmic bridges (CBs) (Elkouby et al., 2016). These CBs contained nonacetylated microtubules (Elkouby et al., 2016), a characteristic of the abscission stages of late cytokinesis (Menon et al., 2014; Wickstrom et al., 2010). The germline cyst originally forms by delaying the completion 
of cytokinesis, leaving cells connected, but how the cell cycle program is modified in the cyst forming cells is unknown. These late zygotene-early pachytene oocytes likely complete cytokinesis and undergo abscission as they separate from the cyst (Elkouby et al., 2016). A modification to the cell cycle could be reversed at these stages to allow abscission and cyst separation. Intriguingly, a modification of the cytokinesis program has been demonstrated in the Drosophila testis, where abscission completion also required the action of follicle cells (Lenhart \& DiNardo, 2015). In the ovary, during early folliculogenesis follicle cells are recruited to newly individual oocytes. A potential involvement of follicle cells in abscission could suggest that cyst separation and folliculogenesis initiation are mechanistically coupled, but this remains to be investigated. Altogether, although the cyst provides the context of early oocyte differentiation, how its organization is regulated is largely unknown. Analyzing the processes of cyst formation and separation in the future will be important to understand early oogenesis.

\section{The zygotene chromosomal bouquet configuration}

A major goal of meiosis I is the recombination of homologous chromosomes to increase genetic diversity and fitness. Before chromosomes can recombine they need to find and pair with their homolog and establish appropriate physical connections by the synaptonemal complex. During the zygotene stages of early meiotic prophase, rapid chromosomal movements facilitate homology searches for their correct pairing. At leptotene-zygotene stages, a unique connection between nuclear telomeres, a Sun domain protein on the inner NE, a KASH domain protein on the outer NE, and microtubules in the cytoplasm is key for these movements (Fig. 2A). Perinuclear microtubules movements in this way drive the rotation of telomeres around the inner NE, tumbling entire chromosomes and thus allowing for inter-chromosomal interactions that test for homology. Ultimately, telomeres cluster at one pole of the NE and form the chromosomal bouquet configuration (Fig. 2A). Telomere clustering ceases their rotation around the $\mathrm{NE}$ and stabilizes the interactions between homologues chromosomes that initiated during their movements, reinforcing their pairing and preparing for recombination at the following pachytene stage. This mechanism is universally conserved from yeast to mammals (Chikashige et al., 2006; Ding et al., 2007; Morimoto et al., 2012; Sato et al., 2009). Some species have developed variations to this mechanism. In Drosophila, chromosome pairing occurs during the mitotic divisions that precede meiosis and utilizes centromeres instead of telomeres (Christophorou et al., 2015; Christophorou et al., 2013; Lake \& Hawley, 2012). In C. elegans, pairing occurs during meiosis, but telomeres are again replaced by other specialized chromosomal regions, called pairing centers (Sato et al., 2009). However, chromosomal movements still depend on microtubules via the same chromosomes-Sun/ KASH-microtubule connection in these species (Christophorou et al., 2015; Hiraoka \& Dernburg, 2009; Penkner et al., 2009; Sato et al., 2009). An exception to this conserved model in observed in S. cerevisiae where actin filaments and not microtubules are required (Trelles-Sticken et al., 2005).

\section{The mechanics of telomere nuclear envelope attachment in bouquet formation}

The bouquet formation mechanism described above requires telomere (or other specialized chromosomal regions) attachment to the Sun protein on the inner NE. Indeed, in sun $1 \%$ mouse spermatocytes and C. elegans oocytes, telomeres are not attached

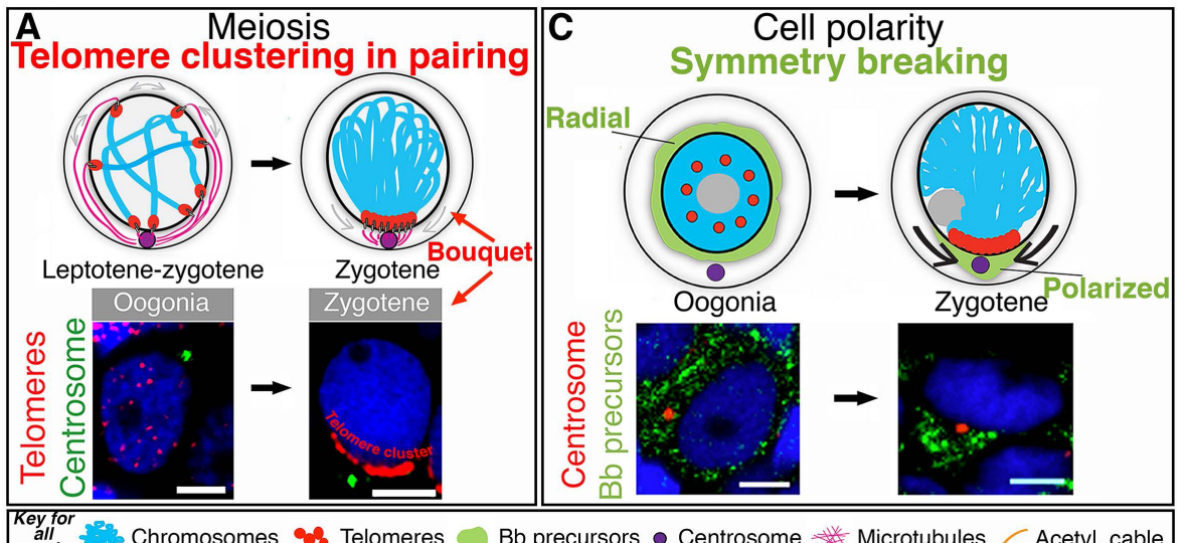

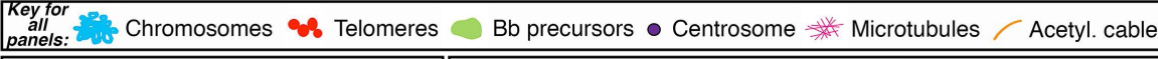

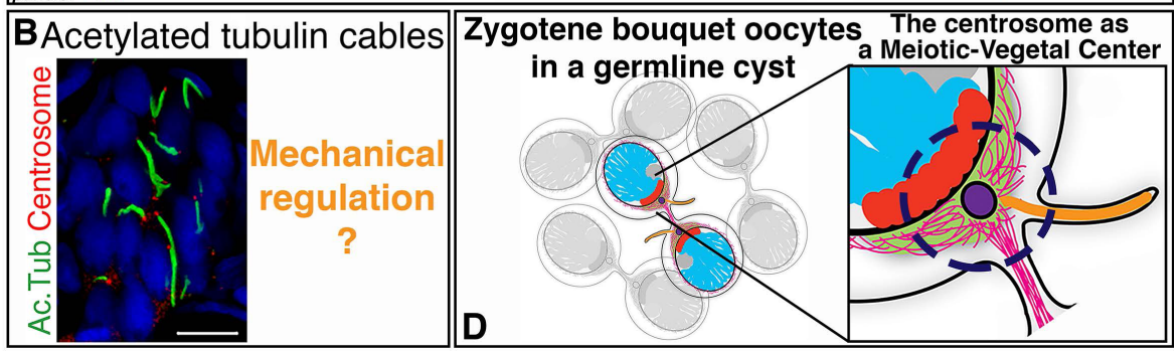

Fig. 2. Early events in oocyte differentiation and the meiotic-vegetal center (MVC). (A) Telomere dynamics during chromosomal pairing and bouquet formation. Telomeres are found randomly intranuclearly at the pre-meiotic oogonia stage (bottom left), then attach to the NE (top left) at meiosis onset, rotate around the NE and cluster at zygotene (note grey arrows), forming the bouquet (top right and bottom right). Telomeres attach to SUN1/KASH complexes on the NE, which associate with centrosome based microtubules during bouquet formation. Scale bar, $5 \mu \mathrm{m}$. (B) Detection of zygotene specific acetylated tubulin cables that emanate from oocytes centrosomes and could mechanically regulate the rapid bouquet movements. Scale bar, $10 \mu \mathrm{m}$. (C) Oocyte symmetry breaking. Bb precursors transition from radial perinuclear distribution at premeiotic oogonia stages (left top and bottom) to a polarized localization around the centrosome and apposing the bouquet telomere cluster at zygotene stages (top right and bottom right). Scale bar, 5 um. (D) The Meiotic-Vegetal Center in the zygotene oocyte. The zygotene centrosome as a cellular organizer that couples meiotic telomere clustering with polarizing Bb formation, is connected to the acetylated tubulin cables, and localized adjacent to cytoplasmic bridges (magenta microtubules cables) that connect oocytes in the zygotene cyst. The number of connections a single oocyte has with other sister oocytes in the cyst is unknown. For simplicity, only a pairwise connection is shown, and the indicated cytoplasmic bridge only refers to the last mitotic division in the cyst. Images at the bottom of (A,C) and in (B) are modified from Elkouby et al. (2016). 
to the NE, chromosomes do not rotate around in the nucleus and synapse is abrogated (Ding et al., 2007; Penkner et al., 2009; Shibuya, Ishiguro, et al., 2014). Telomere binding to Sun1 is mediated by distinct proteins in yeast and multi-cellular eukaryotes, but in an analogous mechanism. In the fission yeast, two inner NE proteins, Bqt3 and Bqt4, bind telomeric proteins and mediate their binding by a Sun/KASH complex (Chikashige et al., 2006). In the budding yeast, the NDJ1 protein functions similarly (Conrad et al., 1997; Trelles-Sticken et al., 2000). However, Bqt3,4, and Ndj1 are yeast specific proteins and neither homologs or analogs have been identified in vertebrates.

A series of recent breakthroughs in mice spermatocytes identified three meiosis specific proteins, Terb1, Terb2 and Majin that mediate an analogous mechanism via interaction with the ubiquitous telomeric protein Trf1 (Shibuya et al., 2015; Shibuya, Ishiguro, et al., 2014). Majin is a tail-anchored protein with a single transmembrane domain that is bound to the inner NE with its Nterminus sticking into the nucleoplasm. Prior to leptotene, Majin binds and sequesters Terb1 and Terb2 to the NE. Majin directly binds the $\mathrm{C}$-terminus of Terb2, and Terb1 binds Terb2 $\mathrm{N}$-terminus. Thus, Terb2 scaffolds Terb1 to Majin. During leptotene-zygotene stages, Terb1 recruits telomeres to the Majin/Terb2/Terb1 complex by binding both the telomeric protein Trf1 and telomeric DNA via a MYB DNA binding domain at its $\mathrm{C}$-terminus. Upon recruitment of telomeres, Majin further binds telomeric DNA via a basic domain near its transmembrane domain, reinforcing the complex. Once this complex is stabilized, Terb1 can bind a nearby Sun1 protein. In this way both Majin and the Sun/KASH complex reinforce telomere attachment to the NE. This engagement to Sun1 can now facilitate the bouquet movements, as it links telomeres to cytoplasmic perinuclear microtubules. In C. elegansand S. pombe, the Sun1 partner KASH protein was associated to microtubules by the Dynein motor protein (Chikashige et al., 2006; Sato et al., 2009), and the KASH-Dynein-microtubule association is likely conserved (Starr \& Fridolfsson, 2010).

\section{Cellular regulation of bouquet formation}

What induces telomere attachment at leptotene-zygotene stages to initiate this mechanism? Telomere attachment to the NE has been also shown to be regulated by phosphorylation of Sun1 $\mathrm{N}$-terminus domain in both mouse spermatocytes and oocytes (Ortega et al., 2003; Viera et al., 2015; Viera et al., 2009) and in C. elegans (Penkner et al., 2009). In mice, Sun1 phosphorylation is induced by Cdk2. cdk2 $2^{--}$mice are viable, but sterile, demonstrating Cdk2 meiosis specific functions (Ortega et al., 2003; Viera et al., 2015; Viera et al., 2009). In cdk2/- spermatocytes and oocytes, telomeres do not localize to Sun1 on the NE and synapse is abrogated (Ortega et al., 2003; Viera et al., 2015; Viera et al., 2009). Importantly, Cdk2 purified from testes was shown to phosphorylate the $\mathrm{N}$-terminus of Sun1 in in-vitro Kinase assays (Viera et al., 2015).

CDK2 in turn is regulated by the atypical Cdk activator, RingoA (Mikolcevic et al., 2016). RingoA knock out mice are also viable sterile and phenocopy $c d k 2^{-/-}$aberrations of telomere attachment (Mikolcevic et al., 2016). Importantly, RingoA protein localizes to telomeres during leptotene-zygotene and unloads from telomeres at pachytene, and was proposed to function specifically in their attachment to Sun1 (Mikolcevic et al., 2016). Importantly, RingoA co-localized with Cdk2 on telomeres and their interaction in testes was demonstrated by reciprocal coimmunoprecipitation experiments (Mikolcevic et al., 2016). Moreover, RingoA was required for Cdk2 localization to telomere in-vivo, and boosted Sun1 $\mathrm{N}$-terminal phosphorylation on Ser48 by Cdk2 in kinase assays (Mikolcevic et al., 2016). Therefore, RingoA seems to activate Cdk2 phosphorylation of Sun1, and induces telomere attachment to Sun1 and the NE downstream.

\section{Primary cilia-like structures and mechanical forces in bou- quet regulation?}

The nuclear events of the bouquet configuration are now well understood. Much less is known about the functions of microtubules and the centrosome as the cytoplasmic counterpart of the bouquet. In C. elegans, the dynein motor protein was shown to localize to the microtubules-KASH protein connection sites, where it repelled the clustering of such sites (Sato et al., 2009). This was proposed to act as a licensing mechanism, providing counter forces that only correct homologous pairing with sufficient affinity would overcome (Sato et al., 2009). What regulates the centrosome and the perinuclear movements of its radiated microtubules in vertebrates is unknown. What initiates the movements and how they are coordinated with the ultimate telomere clustering and synapse progression remains to be uncovered.

Interestingly, a novel cytoskeletal organization specific to the zygotene cyst has been recently discovered that could be involved in cytoplasmic regulation of the bouquet. Prominent cables of acetylated microtubules of varying lengths were detected that emanated from the centrosome (Elkouby et al., 2016) (Fig. 2B). These acetylated cables were absent from the oogonial cyst, but detected as a few short cables in the leptotene cyst, then fully elaborated in the zygotene cyst, and finally not detected at pachytene stage. The structure and function of these cables is still unclear, but the detection of the acetylated cables as extending from the oocyte centrosome highly resembles the structure of a primary cilium. A primary cilium is comprised of an axoneme, a structure composed of stereotypically packed cables of acetylated microtubules, that emanates from the centrosome and extends as a cellular protrusion into the extracellular space (Reiter et al., 2012; Satir \& Christensen, 2007).

Most primary cilia are based from a centrosome that is localized to the cell cortex adjacent to the plasma membrane, but examples of a more internally based cilia exist (Malicki \& Avidor-Reiss, 2014). During mammalian spermatogenesis, a specialized primary cilium extends from a centrosome that is localized to the nuclear periphery deeper in the cytoplasm vicinity (Fawcett et al., 1970) strikingly similar to the acetylated cables in the zygotene oocytes. Such an internally based type of primary cilia is termed cytoplasmic cilia (Malicki \& Avidor-Reiss, 2014). The oocytes zygotene cables have a common structure, but can vary in length. While some appear as conventional primary cilia, other are longer and could represent an exceptionally long primary cilia subtype. It is also possible that these cables comprise internal cytoplasmic cilia that do not protrude away from the cell, but could extend within its cytoplasm. Whether the acetylated cable comprise cilia, and of what type remains to be investigated. A potential function for primary cilia in bouquet regulation would be intriguing.

The primary cilium can execute mechanical functions in the cell (Satir \& Christensen, 2007). Mechanical forces likely generate, or are generated by, the formation of the zygotene chromosomal 
bouquet, when centrosome based microtubules rotate around the nucleus, where they bind chromosome via their telomeres and shuffle them intranuclearly. A primary cilium that connects to the centrosome on the other side may be involved in generating or regulating these bouquet forces. A primary cilium could function as an anchor point for the movements and provide counter forces. It could regulate movements direction and stabilize telomere clustering. Once clustering is achieved, a primary cilium could halt microtubules movements. Additionally, during bouquet stages the nucleus takes most of the oocytes volume, and cytoplasmic volume is relatively small, further increasing the potential impact of bouquet movements on the cell. In this context, a mechanical primary cilium could also stabilize other cellular structures or simply keep the entire oocyte from rotating around, protecting it from physical damage.

A primary cilium could also mediate cell-cell signaling (Satir \& Christensen, 2007). The synchronous formation of acetylated cables in the cyst could mediate an unknown signal to synchronize oocytes development within the cyst.

\section{The bouquet as a central cellular organization in oocyte differentiation}

Mechanisms of bouquet formation are mostly characterized in mouse spermatocytes, but are likely conserved in oocytes and across species. Intriguingly, bouquet mechanisms could be coopted for other processes in meiotic gamete differentiation. In the fission yeast, bouquet formation and normal telomere localization of telomeric proteins during the bouquet regulated the integrity of the spindle pole body, and its spindle formation in the meiotic division following prophase I (Tomita \& Cooper, 2007). In zebrafish oocytes, where animal-vegetal polarity is key to embryonic development and has been traced to the onset of meiosis, bouquet formation is required for the initial symmetry-breaking of the oocyte (Elkouby et al., 2016). Similarly, in oocytes of the insect Thermobia, the forming Balbiani body was detected being aligned to the bouquet configuration (Tworzydlo, Kisiel, et al., 2016). The theme arising is of a bouquet organization of broader cellular significance, functioning in chromosomal pairing, but also in other key developmental aspects of young gametes, at the nexus of their early differentiation.

\section{The oocyte animal-vegetal axis and its roles in embryonic development}

In non-mammalian vertebrates, the early one-cell stage embryo presents an obvious polarization along the animal-vegetal (AV) axis, with the cytoplasm and nucleus segregated to the animal pole and the yolk vegetally localized. The AV axis lays the foundation for shaping the embryo into the typical bilaterian vertebrate body template during gastrulation. However, it is preceded by an earlier polarity, manifested by the segregation of specific mRNAs and proteins to either pole of the oocyte. These polarized components provide crucial information for the early developing embryo. Importantly, the early polarity of the egg and embryo originates in early oogenesis.

\section{The zebrafish animal-vegetal axis}

During fertilization in zebrafish and in many other animals, the sperm entry point is predetermined or predominant to a region in the animal pole hemisphere (Grey et al., 1974; Hart et al., 1992; Motosugi et al., 2006; Piotrowska \& Zernicka-Goetz, 2001). This region is determined in zebrafish by a specialized follicle cell at the animal pole of the oocyte that makes a structure called the micropyle, through which the sperm enters the egg (Amanze \& lyengar, 1990). The single micropyle in the zebrafish egg ensures monospermy. While the micropyle is evident at stage III of oogenesis, its formation is linked to early polarization of the oocyte. In zebrafish, two mutant genes have been identified that affect oocyte and egg polarity, bucky ball (buc) and macf1(microtubule actin crosslinking factor 1 ). In buc ${ }^{-/}$mutant oocytes the vegetal pole is not specified and animal mRNAs are expanded radially. Furthermore, not one but multiple follicle cells around the oocyte are specified to form micropyles (Marlow \& Mullins, 2008b). Indeed, these oocytes develop into non-polarized eggs that undergo polyspermy at fertilization and die soon thereafter (Marlow \& Mullins, 2008b). While the underlying mechanism is unknown, it is clear that specification of a single micropylar-forming follicle cell depends on oocyte polarization. Bucky ball (Buc) has been shown to function in the oocyte and to act cell non-autonomously to restrict specification of the micropylar-forming follicle cell (Heim et al., 2014; Marlow \& Mullins, 2008b).

The oocyte and egg vegetal pole harbors a set of factors that regulate the formation of the dorsal-ventral (DV) axis. The DV axis is formed by the induction of the dorsal organizer on the future dorsal side of the embryo. The dorsal organizer is induced by activation of a Wnt signaling pathway (Langdon \& Mullins, 2011). While other Wnt ligands act in Xenopus (Cha et al., 2008; Cha et al., 2009; Tao et al., 2005), in zebrafish the dorsal determinant is likely the Wnt8 ligand (Lu et al., 2011). Upon egg activation, microtubules reorganize to form parallel arrays at the vegetal pole with a directionality towards the future dorsal side of the embryo (Tran et al., 2012). The Grip2a protein is required for this reorganization (Ge et al., 2014). Once this network is established, wnt8 mRNA is asymmetrically trafficked to the future dorsal side in a manner that depends on the microtubule motor linker protein Syntabulin (Nojima et al., 2010; Nojima et al., 2004). Importantly, wnt8 mRNA first localizes to the vegetal pole in early oocytes via a structure called the Balbiani body (Lu et al., 2011), which specifies the vegetal pole in stage I oocytes (see section 6). Interestingly, the mRNAs of grip2a and syntabulin also localize vegetally via the Balbiani body (Ge et al., 2014; Nojima et al., 2010).

Other factors localized to the oocyte vegetal pole function in establishing the germline. Germ cells in zebrafish and Xenopus are specified by the inheritance of germ cell fate determinants, called germ plasm (Kobayashi et al., 1994)(reviewed (Extavour \& Akam, 2003). In zebrafish, the germ plasm aggregates at the marginal ends of the cleavage furrows of the 2- and 4-cell stage embryo (Braat et al., 1999; Knaut et al., 2000; Riemer et al., 2015a; Yoon et al., 1997). Germ plasm components are initially localized to the vegetal pole by the Balbiani body (Kosaka et al., 2007). However, while the dazl germ plasm mRNA remains localized at the vegetal cortex throughout oogenesis, other $m$ RNAs redistribute and vasa, for example, is re-localized radially at the egg cortex prior to aggregation in the embryo (Kosaka et al., 2007).

Altogether, the vegetal pole provides vital information for multiple aspects of the embryonic body plan. Thus the formation of the AV axis during oogenesis is of tremendous developmental importance. For further discussion of embryonic contributions of maternally 
localized components see (Escobar-Aguirre et al., 2017). The oocyte AV axis has been observed in vertebrates for two centuries and requires establishment of cell polarity during oogenesis by the Balbiani body (Bb). However, the origins of oocyte polarization and $\mathrm{Bb}$ formation have only very recently been uncovered. I will discuss these findings in the next sections.

\section{The Balbiani body - a universal feature of differentiating oocytes}

The Balbiani body $(\mathrm{Bb})$ is a large RNA-protein granule that is universally conserved in oocytes of insects (Cox \& Spradling, 2003; Jaglarz et al., 2003), arthropods (Jedrzejowska \& Kubrakiewicz, 2007), fish (Marlow \& Mullins, 2008b), frogs (Dumont, 1978), birds (Carlson et al., 1996; Rodler \& Sinowatz, 2013; Ukeshima \& Fujimoto, 1991), rodents (Pepling et al., 2007; Weakley, 1967), primates (Barton \& Hertig, 1972), and humans (Albamonte et al., 2013; Hertig, 1968). In all cases ultrastructure analysis showed that the $\mathrm{Bb}$ was composed of aggregated mitochondria and electron dense material, likely corresponding to RNA, and this aggregate was always found in the nuclear periphery. The $\mathrm{Bb}$ has been most studied in Xenopus and zebrafish, where Bb localization of specific mRNAs, proteins, and mitochondria are directly demonstrated and its polarization roles are readily evident (reviewed in (Escobar-Aguirre et al., 2017). While Bb formation has been poorly understood for over two centuries, the mechanism of oocyte symmetry breaking events that lead to its formation have been recently discovered (Elkouby et al., 2016) and I discuss them below. Interestingly, the mouse $\mathrm{Bb}$ contains the Trailer Hitch protein, a member of an mRNA regulating $\mathrm{mRNP}$ complex, possibly indicating a conserved role in mRNA regulation (Pepling et al., 2007). However, Drosophila Trailer Hitch is also an endoplasmic reticulum (ER) resident protein (Wilhelm et al., 2005), and could therefore simply represent the enriched $\mathrm{ER}$ in the mouse $\mathrm{Bb}$, rather than specifically regulating $\mathrm{Bb}$ mRNAs. Furthermore, its localization was not addressed in post $\mathrm{Bb}$ stages to test for polarized localization. It is still unclear whether the $\mathrm{Bb}$ polarizes the early mammalian oocyte. However, a role for the $\mathrm{Bb}$ in the culling for fit oocytes has been recently proposed (Lei \& Spradling, 2016) in the mouse and is discussed below.

\section{Zebrafish Balbiani body and animal-vegetal polarization}

Two pathways deliver mRNA-protein (mRNPs) granules to the vegetal pole during oogenesis: the Balbiani body pathway, which initially determines the vegetal pole, and the "late pathway", which localizes mRNAs to the defined vegetal pole (Escobar-Aguirre et al., 2017). The Balbiani body (Bb) is an aggregate of mRNPs and mitochondria that initially forms adjacent to the nucleus, enlarges and resides in the cytoplasm, and then localizes to the oocyte cortex, where it dissociates (Bontems et al., 2009b; Elkouby et al., 2016; Gupta et al., 2010b; Heim et al., 2014; Marlow \& Mullins, 2008a; Riemer et al., 2015b). Prior to the arrival of the $\mathrm{Bb}$ to the plasma membrane, the oocyte cortex is still radially symmetric. Only when the $\mathrm{Bb}$ associates with the cortex, disassembles, and docks its contents to the membrane, is this cortex region defined as the vegetal pole. Thus, it is the $\mathrm{Bb}$ that first establishes the definitive AV axis of the oocyte.

Very little is known about the molecular mechanisms that govern Bb formation, its cortical localization, and finally its disassembly and cortical tethering of its mRNP cargo. Forward maternal-effect genetic screens in zebrafish recovered two genes that regulate some of these processes, bucky ball (buc) (Marlow \& Mullins, 2008a) and microtubule actin cross-linking factor 1 (macf1; also called magellan) (Gupta et al., 2010b). Buc is the only known protein required for $\mathrm{Bb}$ formation. Indeed, in buc ${ }^{-/}$mutant oocytes, the $\mathrm{Bb}$ does not form and vegetally-fated mRNAs disperse in the cytoplasm, while animally-fated mRNAs expand radially (Bontems etal., 2009b; Heim et al., 2014; Marlow \& Mullins, 2008a; Riemer et al., 2015b). The Buc protein localizes to the Bb (Elkouby et al., 2016; Heim et al., 2014; Nijjar \& Woodland, 2013; Riemer et al., 2015b) and can bind to the Rbpms2 (Hermes) mRNA binding protein (Heim et al., 2014; Nijjar \& Woodland, 2013). Buc structure and potential mechanism of function in $\mathrm{Bb}$ assembly are discussed below.

Complementary to Buc function, Macf1 is required for the $\mathrm{Bb}$ to localize to the oocyte cortex and disassemble. In macf/mutants the $\mathrm{Bb}$ does form, but fails to localize to the oocyte plasma membrane and disassemble, thus trapping the vegetally-fated mRNAs within the cytoplasm and preventing their final localization (Gupta et al., $2010 b)$. During its cortical localization, as well as its disassembly while docking mRNAs to the cortex, the Bb may interact with various cytoskeletal elements. Microtubules form an elaborated network in Xenopus oocytes cytoplasm (Gard, 1991, 1999), while actin forms a cortical network in zebrafish and Xenopus, and is also detected intranuclearly in zebrafish (Gard, 1999; Gupta et al., 2010a; Marlow \& Mullins, 2008b), and cytokeratins were detected in the Xenopus $\mathrm{Bb}$ (Gard et al., 1997). Consistent with its phenotype, the Macf1 protein is a member of the spectraplakin family, and may mediate microtubule and actin connections (Escobar-Aguirre et al., 2017; Gupta et al., 2010b). buc ${ }^{-/}$and macf1/- mutants demonstrate the importance of the $\mathrm{Bb}$ for oocyte polarization. Oocytes of both mutants develop into symmetrical eggs, with a radially expanded- or multiple ectopic animal poles and no vegetal pole, that do not survive past early cleavage stages (Marlow \& Mullins, 2008a). Moreover, the dorsal determinants and germ plasm discussed above, all localize to the vegetal pole via the $\mathrm{Bb}$, further demonstrating its developmental roles.

Several Bb-localized mRNAs have been identified in zebrafish, including buc (Heim et al., 2014), germ plasm mRNAs like dazl, vasa and nanos (Kosaka et al., 2007), and dorsal determinants and dorsalizing machinery mRNAs like wnt8, syntabulin and grip2a (Ge et al., 2014; Nojima et al., 2010) (Lu et al., 2011). Several more have been identified in Xenopus, including $d d x 25$, germes, $d d x 59$, xpat, xlsirt and pcsk6 (Houston, 2013). Moreover, microarray analysis on isolated vegetal cortices from fully grown Xenopus oocytes predicts 275 different localized transcripts (Cuykendall \& Houston, 2010). In this study enrichment of transcripts in isolated vegetal cortices was compared to whole oocytes and transcripts levels were not tested in other regions exclusively, like isolated animal cortices. Localization was not validated for all transcripts. Nonetheless, while these transcripts can localize either via the $\mathrm{Bb}$ or by the late pathway, this analysis suggests that significantly more mRNAs localize to the vegetal pole via the Bb.

The $\mathrm{Bb}$ also contains the Buc protein (Elkouby et al., 2016; Heim et al., 2014; Riemer et al., 2015b), as well as RNA binding proteins like Rbpms2 (Hermes) (Marlow \& Mullins, 2008a; Song et al., 2007) and the scaffold protein GasZ (Elkouby et al., 2016; Marlow \& Mullins, 2008a; Yan et al., 2004). However, the molecular assembly of mRNPs into the Bb is still unknown in zebrafish. In Xenopus, a mitochondrial cloud localizing element (MCLE) is 


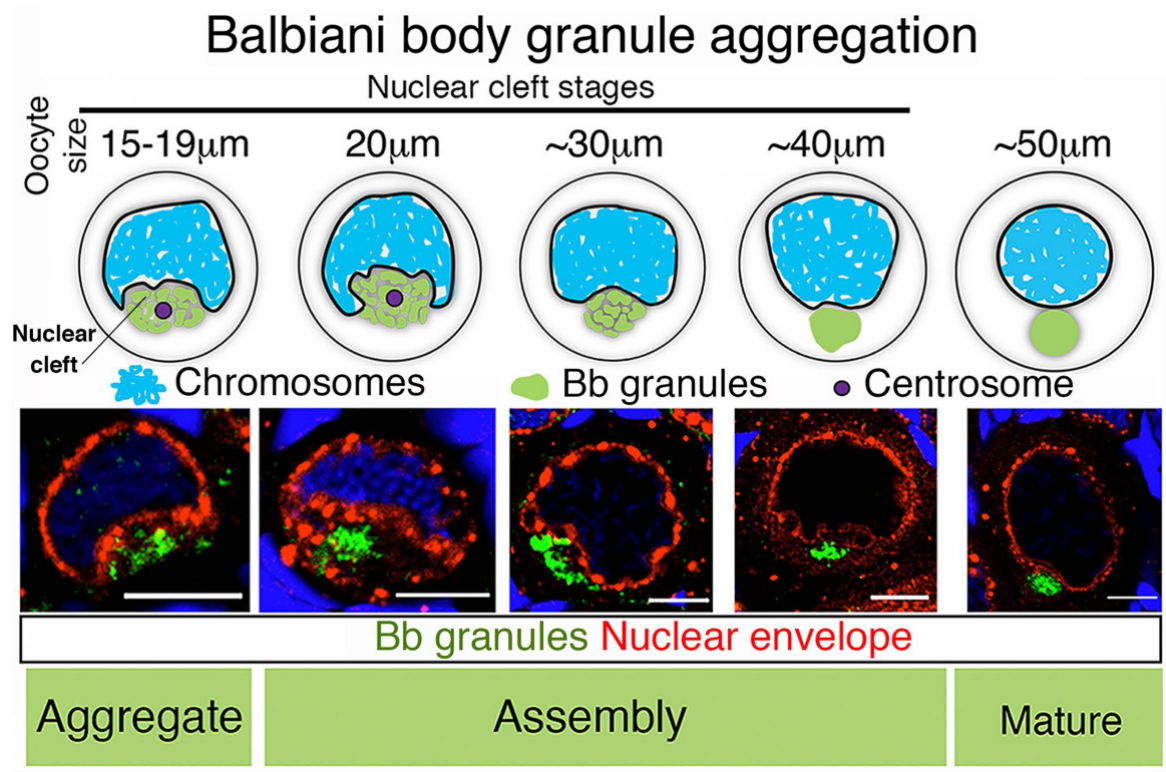

Fig. 3. The prion-like aggregation of granules in forming the Balbiani body (Bb). Upon the symmetry breaking of the oocyte (Fig. 2C), a nuclear cleft forms apposing the meiotic-vegetal center (MVC). Bb granules are aggregated in the nuclear cleft where they are nucleated around the MVC by the prion-like protein Bucky ball. The Bb assembles within the nuclear cleft that gradually rounds out as the oocyte grows (note oocyte sized on top) and gives rise to the mature Bb, which was shown in Xenopus to be of an amyloid structure. Scale bar, 5 um in two left images, and $10 \mu \mathrm{m}$ in right three images. Images are modified from Elkouby et al. (2016). premeiotic oogonia stage to localization around the centrosome in the cytoplasm apposing the telomere cluster of the bouquet (Fig. 2C).

During the bouquet stage, the centrosome localizes specifically in the cytoplasm apposing the telomere cluster, and organizes microtubules to radiate towards and around the nucleus, (Elkouby et al., 2016), consistently with their organization in the bouquet of mouse and zebrafish spermatocytes (Saito et al., 2014; Shibuya, Morimoto, et al., 2014), and where they likely bind Sun/KASH-telomere complexes, and facilitate chromosomal movements (Chikashige et al., 2006; Ding et al., 2007; Mikolcevic et al., 2016; Morimoto et al., 2012; Page \& Hawley, 2003; Saito et al., 2014; Sato et al., 2009; Scherthan, 2001; Shibuya et al., 2015; Shibuya, Ishiguro, et al., 2014; Trelles-Sticken et al., 2000; Viera et al., 2015). Strikingly, microtubules were concomitantly required to cluster the telomeres of the bouquet and localize the $\mathrm{Bb}$ mitochondria precursors, demonstrating that these nuclear and cytoplasmic events are mechanistically coordinated. Therefore, the bouquet stage centrosome functions as a global cellular organizer that couples meiotic genetic events with oocyte patterning, termed the meiotic-vegetal center (MVC; Fig. 2D).

found in the 3'UTR of several Bb mRNAs and is required for their $\mathrm{Bb}$ localization (Escobar-Aguirre et al., 2017). Deletion analysis of the zebrafish dazl 3'UTR revealed a proximal fragment that is required for $\mathrm{Bb}$ localization (Kosaka et al., 2007). However, it is not clear whether common cis consensus sequences mediate $\mathrm{Bb}$ mRNA localization in zebrafish.

Despite the tremendous developmental importance of the vegetal pole and the universal conservation of the $\mathrm{Bb}$, how the $\mathrm{Bb}$ is formed as a prerequisite to vegetal pole formation has been unclear. The earliest detection of polarity has been observed with the detection of the mature $\mathrm{Bb}$ at mid diplotene, and the preceding cellular events have been long overlooked until very recently.

\section{Symmetry-breaking of the zebrafish oocyte - oocyte patterning is coupled with meiosis}

The oocyte symmetry breaking that leads to $\mathrm{Bb}$ formation and oocyte polarization was recently traced to the zygotene bouquet stages at the onset of meiosis (Elkouby et al., 2016) (Fig. 2C). The zygotene stage presents a nuclear asymmetry in which all telomeres are clustered on one side of the NE, while the free looping ends of chromosomes face the opposing side (Scherthan, 2001). This configuration, called the chromosomal bouquet, is a universal meiotic feature that promotes chromosomal synapsis (Chikashige et al., 2006; Ding et al., 2007; Elkouby et al., 2016; Page \& Hawley, 2003; Saito et al., 2014; Sato et al., 2009; Scherthan, 2001; TrellesSticken et al., 2000) (Fig. 2A, and see section 5). Since the early $\mathrm{Bb}$ forms intimately adjacent to the nucleus, it was hypothesized that oocyte polarization could be linked to the nuclear asymmetry of the zygotene bouquet (Elkouby et al., 2016). Indeed, oocyte symmetry was found to be broken when $\mathrm{Bb}$ components, such as Buc, GasZ and mitochondria transition from radial distribution in the
Following the zygotene bouquet stage, using immunohistochemistry on fixed ovaries, vital dye staining of live ovaries and ultrastructural analysis, a novel nuclear morphology was detected, where the NE is highly concave and forms a nuclear cleft (Fig. 3) (Elkouby et al., 2016). The nuclear cleft formed apposing the centrosome, which localized in the cleft cytoplasm thereafter (Elkouby et al., 2016). Upon their initial localization, Bb precursors aggregate around the centrosome within the nuclear cleft (Fig. 3). The nuclear cleft then gradually rounds out during early-mid diplotene, giving rise to the mature $\mathrm{Bb}$.

Importantly, the zygotene bouquet symmetry breaking events lie functionally upstream to the only known $\mathrm{Bb}$ regulator, the Bucky ball protein. In buc ${ }^{-/}$oocytes both the bouquet and the $\mathrm{Bb}$ mitochondrial aggregate form normally (Elkouby et al., 2016). Only later during diplotene stages the aggregate disperses. It seems that in the absence of Buc, the Bb mitochondria can localize toand aggregate around the MVC, but then the aggregate fails to mature into the intact spherical $\mathrm{Bb}$ morphology. How then the $\mathrm{Bb}$ assembles within the nuclear cleft?

\section{Balbiani body assembly by prion-like aggregation mRNPs into an amyloid structure}

As discussed above, the Bucky Ball protein nucleates Bb mRNPs in $\mathrm{Bb}$ formation. Intriguingly, the Bucky ball amino acid sequence indicates that it is an intrinsically disordered protein (IDP) (Bontems et al., 2009a; Toretsky \& Wright, 2014). IDPs are proteins that lack a fixed or ordered three-dimensional structure, as their amino acid sequence does not dictate folding into a consistent tertiary structure. IDPs are being increasingly recognized in formation of various mRNP granules. Homologs of the piRNA protein Vasa contain an intrinsically disordered region (IDR) (Nott et al., 2015), and other 
mRNA binding proteins contain IDRs adjacent to their RRM RNA binding domain (Guo \& Shorter, 2015; Zhang et al., 2015). These are thought to promote the phase separation of mRNA granules, where the RRM domain binds RNA, while the IDR comprise the lattice-like meshwork of the phase separating granule (Guo \& Shorter, 2015; Nott et al., 2015; Zhang et al., 2015).

Phase-separated granules are thought to have a structure of a hydrogel. A hydrogel is a polymerized meshwork that can form in vitro by the polymerization of a substrate accumulating over a specific concentration threshold (Han et al., 2012; Toretsky \& Wright, 2014). The content of the hydrogel is therefore less soluble than the remaining cytoplasm (Brangwynne et al., 2009; Han et al., 2012; Toretsky \& Wright, 2014). More physiologically, similar phase separation of mRNP complexes was demonstrated in C. elegans, where embryonic germ plasm P-granules form condensed liquid droplets only in the embryo posterior (Brangwynne et al., 2009; Wang et al., 2014a). The polymerizing substrates of P-granules are the MEG1 and MEG 3 proteins (Wang et al., 2014b). The condensation of mRNPs into a hydrogel-like P-granule and their dissolution were controlled by the phosphorylation state of MEG1, 3 (Brangwynne et al., 2009; Wang et al., 2014a).

As an IDP, Bucky ball could act similarly to IDPs in other granules,

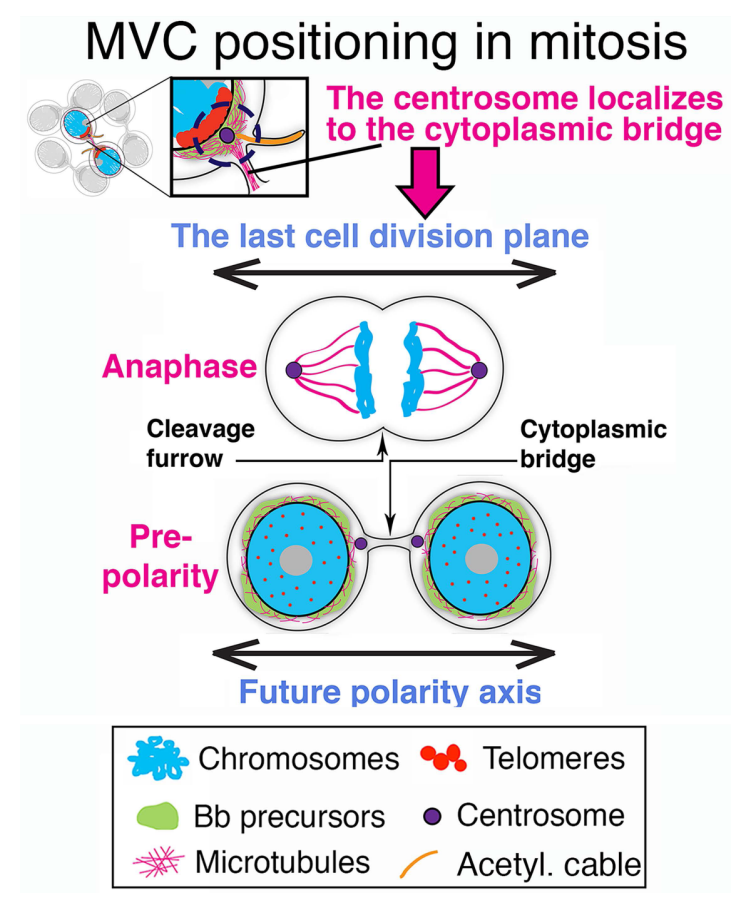

Fig. 4. Potential regulation of meiotic-vegetal center (MVC) and polarization by the last mitotic division in the oogonial cyst. At late zygotene-early pachytene stage oocytes, where cytoplasmic bridges were detected between oocytes, the MVC with already localized Bb components localized adjacent to the cytoplasmic bridge (magenta microtubules cables in inset). Since these cytoplasmic bridges likely mark the division plane of the last mitotic division, it is proposed that the meiotic polarization axis in the oocyte is aligned to the plane of the last mitotic division in the cyst (horizontal arrows). Studies in mice suggest that the centrosome does not change its cellular position during zygotene bouquet movements. It is therefore likely that the centrosome shuttles from its anaphase position of the last division, to become adjacent to the cytoplasmic bridge prior to polarization. by forming a scaffolding phase-separating lattice that aggregates mRNAs and mRNPs during $\mathrm{Bb}$ formation (EscobarAguirre et al., 2017). Such a mechanism was recently suggested for the Buc Xenopus homolog XVelo (Boke et al., 2016). Mature Bbs isolated from Xenopus oocytes exhibited features of an amyloid structure, such as resistance to dissolution at high salt concentration and high temperature, and it stained positively for an amyloid dye in vivo. Furthermore, the $\mathrm{N}$-terminus of $\mathrm{XVelo}$, which is conserved among Buc orthologues (the BUVE in (Bontems et al., 2009b)), contains a prion-like domain that is adjacent to the extended predicted IDR. This domain in XVelo was shown to be necessary and sufficient for $\mathrm{Bb}$ localization in ectopic expression studies in vivo, and formed an SDS resistant amyloid-like structure in vitro.

Interestingly, XVelo could aggregate the $\mathrm{Bb}$ components in vitro and/or in Xenopus egg extracts. For both of which, the XVelo $\mathrm{C}$-terminus was required, suggesting that while the conserved $\mathrm{XVelo} \mathrm{N}$-terminal prion domain is required for the formation of an amyloid-like matrix, its $\mathrm{C}$-terminus is required for its aggregation of putative $\mathrm{Bb}$ components (Boke et al., 2016). The function of the endogenous XVelo prion-like domain in $\mathrm{Bb}$ component aggregation in vivo has not yet been tested, although is expected to cause a failure in $\mathrm{Bb}$ assembly like buc/-null mutant alleles (Bontems et al., 2009b; Elkouby et al., 2016; Marlow \& Mullins, 2008a).

\section{Potential regulation of polarity by cyst mitotic division}

While the symmetry-breaking of the oocyte is executed at zygotene stages, the organization of meiotic oocytes in the germline cyst, suggests earlier regulation of polarization in the oogonial cyst. Indeed, the centrosome MVC (meiotic vegetal center) was localized to the cytoplasm adjacent to the CB (cytoplasmic bridge) in later sister oocytes that were still connected by the CB (Fig. 4) (Elkouby et al., 2016). At this stage, Bb precursors are already aggregated around the centrosome, revealing an alignment of the polarization axis to the oocyte last division plane (Elkouby et al., 2016). Since cytokinesis at these stages completes the division that started in the oogonial cyst, and since the centrosome does not change its cellular position during zygotene stages (Shibuya, Morimoto, et al., 2014), this suggests that prior to polarization, the centrosome likely localizes to the $\mathrm{CB}$ and thus determines the future axis of polarization (Fig. 4).

The germline cyst is constructed by the mitotic oogonial cells that undergo several rounds of incomplete cell divisions, leaving persisting CBs that continue to connect sister cells in the cyst through early meiotic stages. The organization of oogonia and early oocytes in germline cysts, where they are connected by CBs and surrounded by somatic granulosa cells, is a common theme in germ cell development. However, the localization of the centrosome to the $\mathrm{CB}$ prior to its polarization of the oocyte is first direct evidence for a potential role of mitotic cyst division in controlling meiotic oocyte polarization. Polarization thus seems to occur in two steps: first, the centrosome localizes to the cytoplasm adjacent to the CB of oogonia, aligning the future polarity axis to the cell division plane, then, the MVC is activated and polarization in in effect executed during bouquet stages (Elkouby et al., 2016).

Such a dual and dynamic role of the centrosome in cell division and the immediately following polarization during differentiation was beautifully demonstrated in the developing c. elegans gut (Feldman \& Priess, 2012; Yang \& Feldman, 2015). After its microtubule organizing center (MTOC) function during gut precursor cell divi- 
sions, the centrosome re-localizes to the future apical pole of these now differentiating epithelial cells together with polarity proteins (Feldman \& Priess, 2012; Yang \& Feldman, 2015).

Thus, Bb formation, its upstream regulation, and downstream assembly, are interwoven with key events in early oocyte differentiation, from potential regulation by mitotic divisions in the germline cyst, through coupling with chromosomal pairing during the meiotic bouquet, to maturing during folliculogenesis.

\section{The mouse Balbiani body and oocyte survival}

The mouse $\mathrm{Bb}$ has been recently correlated with oocyte survival (Lei \& Spradling, 2016). Consistently with zebrafish (Elkouby et al., 2016), Bb formation was detected at earlier meiotic stages, when oocytes still reside in germline cysts (Lei \& Spradling, 2016). It has been proposed that mouse Bb components, such as Golgi, mitochondria and centrosomes, are transported between oocytes through cytoplasmic bridges in the cyst. This has been deduced by detection of more of these components in certain oocytes in the cyst and their weaker detection in nearby oocytes of the same clone, and localization of some components near cytoplasmic bridges (Lei \& Spradling, 2016). However, these were recorded in still images and live time-lapse analysis was lacking to support this intriguing model. Other technical or biological explanations for such a differential detection have not been ruled out.

In zebrafish, before symmetry breaking, $\mathrm{Bb}$ components are found radially symmetrical at the nuclear periphery of all oocytes in similar levels (Elkouby et al., 2016). In addition, if such a transport mechanism is required for mouse folliculogenesis, then the absence of $\mathrm{CBs}$ is expected to prevent normal folliculogenesis. Interestingly, CBs between oocytes are absent in tex14\% female mice, although they are fertile (Greenbaum et al., 2009). While fewer oocytes are detected in P2.5 tex14\% ovaries, prior to cyst breakdown the number of germ cells in these ovaries is normal and oocytes complete folliculogenesis normally (Greenbaum et al., 2009).

The authors propose that during transport, oocyte that undergo apoptosis deliver their organelles to surviving oocytes that form the $\mathrm{Bb}$ (Lei \& Spradling, 2016). This would suggest that apoptosis is required for folliculogenesis of $\mathrm{Bb}$-positive oocytes. The proteins P53 and P63 are required for meiotic checkpoint-induced apoptosis at around the time of the proposed transport mechanism (Bolcun-Filas et al., 2014). However, while apoptosis in the cyst and folliculogenesis per se were not directly addressed, ovaries of $p 53^{-/}$and $p 63^{-/}$mutants in (Bolcun-Filas et al., 2014) seem to form normal follicles.

In the mouse, oocytes undergo robust apoptosis and only $20 \%$ of initial cells in cysts eventually form follicles (Lei \& Spradling, 2016). Apoptosis is relatively frequent in the mouse germline cyst (Lei \& Spradling, 2016) in comparison with other species like Medaka and Xenopus (Kloc et al., 2004; Nakamura et al., 2010). Bb formation and apoptosis were reported to be mutually exclusive in the mouse ovary (Lei \& Spradling, 2016). It was proposed that Bb formation in an oocyte favors its continuous differentiation and follicle formation and prevents apoptosis, whereas oocytes that do not form a $\mathrm{Bb}$ are fated to undergo apoptosis (Lei \& Spradling, 2016). The notion of the $\mathrm{Bb}$ as a possible marker for fit oocytes could reflect a new important function in mammals. However, a mutual exclusive detection of apoptosis and $\mathrm{Bb}$ formation could also result reciprocally from $\mathrm{Bb}$ degradation by apoptotic processes. It is well possible that $\mathrm{Bb}$ degradation will precede other apoptotic phenotypes, such as nuclei degeneration, especially since mitochondria outer membrane provides the platform for apoptosis initiation (Czabotar et al., 2014; Gillies \& Kuwana, 2014), and mitochondria is highly enriched in the $\mathrm{Bb}$, but this scenario was not addressed.

\section{Coupling of Balbiani body and the chromosomal bouquet formation - a universal theme in oocytes?}

Accumulating recent data on $\mathrm{Bb}$ formation now enable comparison between species and identification of common principles. Findings in zebrafish for the first time connect the $\mathrm{Bb}$ and the bouquet, two universal oocyte features, in establishing cellular polarity by the MVC (Elkouby et al., 2016). The universal conservation of both the $\mathrm{Bb}$ and the zygotene chromosomal bouquet suggests that such a coupling of their formation is also likely conserved. Indeed, a recent report shows that the $\mathrm{Bb}$ of the insect Thermobia domestica is first aggregated apposing the telomere cluster of the Thermobia oocyte zygotene bouquet (Tworzydlo, Marek, et al., 2016). Interestingly, Thermobia ovarioles show a more "vertebrate"-like mode of oogenesis, where all germ cells in the garmarium are fated to become oocytes, as opposed to some becoming nurse cells like in Drosophila (Tworzydlo, Marek, et al., 2016).

Furthermore, recent analysis of $\mathrm{Bb}$ formation in mice oocytes, revealed a formation dynamic that is strikingly similar to that of the zebrafish Bb. The mouse Bb Golgi component was first polarized around the centrosome of in the early germline cyst at E14.5 (Lei \& Spradling, 2016). Additional Golgi and mitochondria continued to aggregate around the centrosome within the germline cyst through stage E18.5 (Lei \& Spradling, 2016). Finally, still much like in zebrafish, the mature mouse $\mathrm{Bb}$ is detected at early diplotene stages of the primordial follicle at P0-P7 (Lei \& Spradling, 2016; Pepling et al., 2007).

These data from mice and Thermobia suggest that the mechanisms revealed in zebrafish oocytes may act in these species as well, highlighting the likely universal coordination of $\mathrm{Bb}$ formation and meiosis by the meiotic vegetal center (MVC).

\section{Concluding remarks}

Recentadvances in our understanding of early oocyte differentiation in various species address long standing questions in the field and allow for a construction of a model for vertebrate oogenesis. The zebrafish ovary arises as a new model where multiple facets of oocyte differentiation, such as regulation of the cell division and the germline cyst, meiosis, establishment of cell polarity, aggregation of mRNP granules and mechanical forces of chromosomal pairing can be readily investigated. The physical properties of the zebrafish juvenile ovary, its high accessibility and the presence of a range of early oocyte stages in an ovary, importantly and uniquely, allows for the investigation of how these multiple processes are coordinated in oocyte differentiation by the MVC (Fig. 2D). The MVC was only recently discovered. Future investigation of its upstream regulation, its mechanistic intersection of polarity and meiosis, its downstream nucleation of the prion-like Bucky ball protein, and its potential mechanical functions via novel cytoskeletal structures, will be immensely important for a better mechanistic view of early oogenesis. Finding new MVC regulator and/or partner proteins will provide a next step for further functional analysis.

Notably, this investigation in the zebrafish ovary has great 
implications of broad interests in cell and developmental biology. The upstream regulation of the centrosome MVC can reveal how mitosis contributes to cell polarity. The mechanisms of prion mRNP aggregation by the centrosome MVC in the oocyte can reveal how prion aggregation is regulated in physiological conditions which is defective in neurodegenerative diseases. The oocyte acetylated cables in meiosis can comprise a new type of primary cilia as a potential novel context for understanding cilia biology and ciliopathies.

A toolbox for the investigation of early oocytes in zebrafish was recently developed (Elkouby \& Mullins, 2017), and include methods for quantitative imaging, in vivo live time-lapse analysis, ovarian culturing and isolation of stage specific oocytes for molecular biology and biochemical analyses. In the near future, using CRISPR/Cas9 genome editing for generating mutants, conditional alleles, and endogenous fluorescently tagged alleles will allow for an extensive investigation by robust reverse genetics and lead to further breakthroughs.

\section{References}

ALBAMONTE, M. I., ALBAMONTE, M. S., STELLA, I., ZUCCARDI, L., and VITULLO, A. D. (2013). The infant and pubertal human ovary: Balbiani's body-associated VASAexpression, immunohistochemical detection of apoptosis-related BCL2 and BAX proteins, and DNA fragmentation. Hum Reprod 28: 698-706.

AMANZE, D., and IYENGAR, A. (1990). The micropyle: a sperm guidance system in teleost fertilization. Development 109: 495-500.

ANDERSON, E. L., BALTUS, A. E., ROEPERS-GAJADIEN, H. L., HASSOLD, T. J., DE ROOIJ, D. G., VAN PELT, A. M., and PAGE, D. C. (2008). Stra8 and its inducer, retinoic acid, regulate meiotic initiation in both spermatogenesis and oogenesis in mice. Proc Natl Acad Sci USA 105: 14976-14980.

ANDERSON, J. L., RODRIGUEZ MARI, A., BRAASCH, I., AMORES, A., HOHENLOHE, P., BATZEL, P., and POSTLETHWAIT, J. H. (2012). Multiple sex-associated regions and a putative sex chromosome in zebrafish revealed by RAD mapping and population genomics. PLoS One 7: e40701.

BARTON, B. R., and HERTIG, A. T. (1972). Ultrastructure of annulate lamellae in primary oocytes of chimpanzees (Pan troglodytes). Biol Reprod 6: 98-108.

BEER, R. L., and DRAPER, B. W. (2013). nanos3 maintains germline stem cells and expression of the conserved germline stem cell gene nanos2 in the zebrafish ovary. Dev Biol 374: 308-318.

BOKE, E., RUER, M., WUHR, M., COUGHLIN, M., LEMAITRE, R., GYGI, S. P.,... MITCHISON, T. J. (2016). Amyloid-like Self-Assembly of a Cellular Compartment. Cell 166: 637-650.

BOLCUN-FILAS, E., RINALDI, V. D., WHITE, M. E., and SCHIMENTI, J. C. (2014). Reversal of female infertility by Chk2 ablation reveals the oocyte DNA damage checkpoint pathway. Science 343: 533-536.

BONTEMS, F., STEIN, A., MARLOW, F., LYAUTEY, J., GUPTA, T., MULLINS, M. C., and DOSCH, R. (2009a). Bucky ball organizes germ plasm assembly in zebrafish. Curr. Biol. 19: 414-422.

BONTEMS, F., STEIN, A., MARLOW, F., LYAUTEY, J., GUPTA, T., MULLINS, M. C., and DOSCH, R. (2009b). Bucky ball organizes germ plasm assembly in zebrafish. Curr Biol 19: 414-422.

BOWLES, J., and KOOPMAN, P. (2007). Retinoic acid, meiosis and germ cell fate in mammals. Development 134: 3401-3411.

BRAAT, A. K., ZANDBERGEN, T., VAN DE WATER, S., GOOS, H. J., and ZIVKOVIC, D. (1999). Characterization of zebrafish primordial germ cells: morphology and early distribution of vasa RNA. Dev Dyn 216: 153-167.

BRANGWYNNE, C. P., ECKMANN, C. R., COURSON, D. S., RYBARSKA, A., HOEGE, C., GHARAKHANI, J.,... HYMAN, A. A. (2009). Germline P granules are liquid droplets that localize by controlled dissolutionjcondensation. Science 324: 1729-1732.

BURGOYNE, P. S., MAHADEVAIAH, S. K., and TURNER, J. M. (2009). The consequences of asynapsis for mammalian meiosis. Nat Rev Genet 10: 207-216.

CARLSON, J. L., BAKST, M. R., and OTTINGER, M. A. (1996). Developmental stages of primary oocytes in turkeys. Poult Sci 75: 1569-1578.
CHA, S. W., TADJUIDJE, E., TAO, Q., WYLIE, C., and HEASMAN, J. (2008). Wnt5a and Wnt11 interact in a maternal Dkk1-regulated fashion to activate both canonical and non-canonical signaling in Xenopus axis formation. Development 135:3719-3729.

CHA, S. W., TADJUIDJE, E., WHITE, J., WELLS, J., MAYHEW, C., WYLIE, C., and HEASMAN, J. (2009). Wnt11j5a complex formation caused by tyrosine sulfation increases canonical signaling activity. Curr. Biol. 19: 1573-1580.

CHIKASHIGE, Y., TSUTSUMI, C., YAMANE, M., OKAMASA, K., HARAGUCHI, T. and HIRAOKA, Y. (2006). Meiotic proteins bqt1 and bqt2 tether telomeres to form the bouquet arrangement of chromosomes. Cell 125: 59-69.

CHRISTOPHOROU, N., RUBIN, T., BONNET, I., PIOLOT, T., ARNAUD, M., and HUYNH, J. R. (2015). Microtubuledriven nuclear rotations promote meiotic chromosome dynamics. Nat Cell Biol 17: 1388-1400.

CHRISTOPHOROU, N., RUBIN, T., and HUYNH, J. R. (2013). Synaptonemal complex components promote centromere pairing in pre-meiotic germ cells. PLOS Genet 9: e1004012.

CONRAD, M. N., DOMINGUEZ, A. M., and DRESSER, M. E. (1997). Ndj1p, a meiotic telomere protein required for normal chromosome synapsis and segregation in yeast. Science 276: 1252-1255.

COX, R. T., and SPRADLING, A. C. (2003). A Balbiani body and the fusome mediate mitochondrial inheritance during Drosophila oogenesis. Development 130 1579-1590.

CUYKENDALL, T. N., and HOUSTON, D. W. (2010). Identification of germ plasmassociated transcripts by microarray analysis of Xenopus vegetal cortex RNA. Dev Dyn 239: 1838-1848.

CZABOTAR, P. E., LESSENE, G., STRASSER, A., and ADAMS, J. M. (2014). Control of apoptosis by the BCL2 protein family: implications for physiology and therapy. Nat Rev Mol Cell Biol 15: 49-63.

DING, X., XU, R., YU, J., XU, T., ZHUANG, Y., and HAN, M. (2007). SUN1 is required for telomere attachment to nuclear envelope and gametogenesis in mice. Dev Cell 12: 863-872.

DRANOW, D. B., TUCKER, R. P., and DRAPER, B. W. (2013). Germ cells are required to maintain a stable sexual phenotype in adult zebrafish. Dev Biol 376: 43-50.

DUMONT, J. N. (1978). Oogenesis in Xenopus laevis (Daudin). VI. The route of injected tracer transport in the follicle and developing oocyte. J Exp Zool 204: 193-217.

ELKOUBY, Y., and MULLINS, M. (2017). Methods for the analysis of early oogenesis in zebrafish. Dev Biol (doi: 10.1016/j.ydbio.2016.12.014)

ELKOUBY, Y. M., JAMIESON-LUCY, A., and MULLINS, M. C. (2016). Oocyte Polarization Is Coupled to the Chromosomal Bouquet, a Conserved Polarized Nuclear Configuration in Meiosis. PLoS Biol 14: e1002335.

ESCOBAR-AGUIRRE, M., ELKOUBY, Y. M., and MULLINS, M. C. (2017) Localization in Oogenesis of Maternal Regulators of Embryonic Development., Adv Exp Med Biol 953: 173-207.

EXTAVOUR, C. G., and AKAM, M. (2003). Mechanisms of germ cell specification across the metazoans: epigenesis and preformation. Development 130:5869-5884.

FAWCETT, D. W., EDDY, E. M., and PHILLIPS, D. M. (1970). Observations on the fine structure and relationships of the chromatoid body in mammalian spermatogenesis. Biol Reprod 2: 129-153.

FELDMAN, J. L., and PRIESS, J. R. (2012). A role for the centrosome and PAR-3 in the hand-off of MTOC function during epithelial polarization. Curr Biol22: 575-582.

GARD, D. L. (1991). Organization, nucleation, and acetylation of microtubules in Xenopus laevis oocytes: a study by confocal immunofluorescence microscopy. Dev Biol 143: 346-362.

GARD, D. L. (1999). Confocal microscopy and 3-D reconstruction of the cytoskeleton of Xenopus oocytes. Microsc Res Tech 44: 388-414.

GARD, D. L., CHA, B. J., and KING, E. (1997). The organization and animal-vegetal asymmetry of cytokeratin filaments in stage VI Xenopus oocytes is dependent upon F-actin and microtubules. Dev Biol 184: 95-114.

GE, X., GROTJAHN, D., WELCH, E., LYMAN-GINGERICH, J., HOLGUIN, C., DIMITROVA, E.,... PELEGRI, F. (2014). HecatejGrip2a acts to reorganize the cytoskeleton in the symmetry-breaking event of embryonic axis induction. Plos Genetics 10: e1004422.

GILLIES, L. A., and KUWANA, T. (2014). Apoptosis regulation at the mitochondrial outer membrane. J Cell Biochem 115: 632-640.

GREENBAUM, M. P., IWAMORI, N., AGNO, J. E., and MATZUK, M. M. (2009). Mouse TEX14 is required for embryonic germ cell intercellular bridges but not female 
fertility. Biol Reprod 80: 449-457.

GREENBAUM, M. P., MA, L., and MATZUK, M. M. (2007). Conversion of midbodies into germ cell intercellular bridges. Dev Biol 305: 389-396.

GREY, R. D., WOLF, D. P., and HEDRICK, J. L. (1974). Formation and structure of fertilization envelope in Xenopus-laevis. Dev Biol 36: 44-61.

GRIFFIN, J., EMERY, B. R., HUANG, I., PETERSON, C. M., and CARRELL, D. T. (2006). Comparative analysis of follicle morphology and oocyte diameter in four mammalian species (mouse, hamster, pig, and human). J Exp Clin Assist Reprod 3: 2.

GUO, L., and SHORTER, J. (2015). It's Raining Liquids: RNA Tunes Viscoelasticity and Dynamics of Membraneless Organelles. Mol Cell 60: 189-192.

GUPTA, T., MARLOW, F. L., FERRIOLA, D., MACKIEWICZ, K., DAPPRICH, J., MONOS, D., and MULLINS, M. C. (2010a). Microtubule actin crosslinking factor 1 regulates the Balbiani body and animal-vegetal polarity of the zebrafish oocyte. Plos Genetics 6(8): e1001073. https://doi.org/10.1371/journal.pgen.1001073

HAN, T. W., KATO, M., XIE, S., WU, L. C., MIRZAEI, H., PEI, J.,... MCKNIGHT, S. L. (2012). Cell-free formation of RNA granules: bound RNAs identify features and components of cellular assemblies. Cell 149: 768-779.

HART, N. H., BECKER, K. A., and WOLENSKI, J. S. (1992). The sperm entry site during fertilization of the zebrafish egg: localization of actin. Mol Reprod Dev32:217-228.

HEIM, A. E., HARTUNG, O., ROTHHAMEL, S., FERREIRA, E., JENNY, A., and MARLOW, F. L. (2014). Oocyte polarity requires a Bucky ball-dependent feedback amplification loop. Development 141: 842-854.

HERTIG, A. T. (1968). The primary human oocyte: some observations on the fine structure of Balbiani's vitelline body and the origin of the annulate lamellae. Am $J$ Anat 122: 107-137.

HIRAOKA, Y., and DERNBURG, A. F. (2009). The SUN rises on meiotic chromosome dynamics. Dev Cell 17: 598-605.

HOUSTON, D. W. (2013). Regulation of cell polarity and RNA localization in vertebrate oocytes. Int Rev Cell Mol Biol 306: 127-185.

HOWE, K., CLARK, M. D., TORROJA, C. F., TORRANCE, J., BERTHELOT, C., MUFFATO, M.,... STEMPLE, D. L. (2013). The zebrafish reference genome sequence and its relationship to the human genome. Nature 496: 498-503.

HOWLEY, C., and HO, R. K. (2000). mRNA localization patterns in zebrafish oocytes. Mech Dev 92: 305-309.

JAGLARZ, M. K., NOWAK, Z., and BILINSKI, S. M. (2003). The Balbiani body and generation of early asymmetry in the oocyte of a tiger beetle. Differentiation 71 : 142-151.

JEDRZEJOWSKA, I., and KUBRAKIEWICZ, J. (2007). The Balbiani body in the oocytes of a common cellar spider, Pholcus phalangioides (Araneae: Pholcidae). Arthropod Struct Dev 36: 317-326.

KLOC, M., BILINSKI, S., DOUGHERTY, M. T., BREY, E. M., and ETKIN, L. D. (2004). Formation, architecture and polarity of female germline cyst in Xenopus. Dev Biol 266: 43-61.

KNAUT, H., PELEGRI, F., BOHMANN, K., SCHWARZ, H., and NUSSLEIN-VOLHARD, C. (2000). Zebrafish vasa RNA but not its protein is a component of the germ plasm and segregates asymmetrically before germline specification. J. Cell. Biol. 149: 875-888

KOBAYASHI, S., AMIKURA, R., and OKADA, M. (1994). Localization of mitochondrial large rRNA in germinal granules and the consequent segregation of germ line. Int J Dev Biol 38: 193-199.

KOSAKA, K., KAWAKAMI, K., SAKAMOTO, H., and INOUE, K. (2007). Spatiotemporal localization of germ plasm RNAs during zebrafish oogenesis. Mech Dev 124: $279-289$

KOUBOVA, J., HU, Y.C., BHATTACHARYYA, T., SOH, Y. Q., GILL, M. E., GOODHEART, M. L.,... PAGE, D. C. (2014). Retinoic acid activates two pathways required for meiosis in mice. Plos Genetics 10: e1004541.

LAKE, C. M., and HAWLEY, R. S. (2012). The molecular control of meiotic chromosomal behavior: events in early meiotic prophase in Drosophila oocytes. Annu Rev Physiol 74: 425-451.

LANGDON, Y. G., and MULLINS, M. C. (2011). Maternal and zygotic control of zebrafish dorsoventral axial patterning. Annu Rev Genet 45: 357-377.

LEI, L., and SPRADLING, A. C. (2013). Mouse primordial germ cells produce cysts that partially fragment prior to meiosis. Development 140: 2075-2081.
LEI, L., and SPRADLING, A. C. (2016). Mouse oocytes differentiate through organelle enrichment from sister cyst germ cells. Science 352: 95-99.

LENHART, K. F., and DINARDO, S. (2015). Somatic cell encystment promotes abscission in germline stem cells following a regulated block in cytokinesis. Dev Cell 34: 192-205.

LEU, D. H., and DRAPER, B. W. (2010). The ziwi promoter drives germline-specific gene expression in zebrafish. Dev Dyn 239: 2714-2721.

LU, F. I., THISSE, C., and THISSE, B. (2011). Identification and mechanism of regulation of the zebrafish dorsal determinant. Proc Natl Acad Sci USA 108: 15876-15880.

MAACK, G., and SEGNER, H. (2003). Morphological development of the gonads in zebrafish. J. Fish Biol. 62: 895-906.

MACQUEEN, A. J., and HOCHWAGEN, A. (2011). Checkpoint mechanisms: the puppet masters of meiotic prophase. Trends Cell Biol 21: 393-400.

MALICKI, J., and AVIDOR-REISS, T. (2014). From the cytoplasm into the cilium: bon voyage. Organogenesis 10: 138-157.

MARLOW, F. L., and MULLINS, M. C. (2008a). Bucky ball functions in Balbiani body assembly and animal-vegetal polarity in the oocyte and follicle cell layer in zebrafish. Dev Biol 321: 40-50.

MARLOW, F. L., and MULLINS, M. C. (2008b). Bucky ball functions in Balbiani body assembly and animal-vegetal polarity in the oocyte and follicle cell layer in zebrafish. Dev Biol 321: 40-50.

MATOVA, N., and COOLEY, L. (2001). Comparative aspects of animal oogenesis Dev Biol 231: 291-320.

MENON, M. B., SAWADA, A., CHATURVEDI, A., MISHRA, P., SCHUSTER-GOSSLER, K., GALLA, M.,... GAESTEL, M. (2014). Genetic deletion of SEPT7 reveals a cell type-specific role of septins in microtubule destabilization for the completion of cytokinesis. PLoS Genet 10: e1004558.

MIKOLCEVIC, P., ISODA, M., SHIBUYA, H., DEL BARCO BARRANTES, I., IGEA, A., SUJA, J. A.,... NEBREDA, A. R. (2016). Essential role of the Cdk2 activator RingoA in meiotic telomere tethering to the nuclear envelope. Nat Commun 7: 11084

MORIMOTO, A., SHIBUYA, H., ZHU, X., KIM, J., ISHIGURO, K., HAN, M., and WATANABE, Y. (2012). A conserved KASH domain protein associates with telomeres, SUN1, and dynactin during mammalian meiosis. J Cell Biol 198: 165-172.

MOTOSUGI, N., DIETRICH, J. E., POLANSKI, Z., SOLTER, D., and HIIRAGI, T. (2006). Space asymmetry directs preferential sperm entry in the absence of polarity in the mouse oocyte. PLoS Biol 4: e135.

NAKAMURA, S., KOBAYASHI, K., NISHIMURA, T., HIGASHIJIMA, S., and TANAKA, M. (2010). Identification of germline stem cells in the ovary of the teleost medaka. Science 328: 1561-1563.

NIJJAR, S., and WOODLAND, H. R. (2013). Protein interactions in Xenopus germ plasm RNP particles. PLoS One 8: e80077.

NOJIMA, H., ROTHHAMEL, S., SHIMIZU, T., KIM, C. H., YONEMURA, S., MARLOW, F. L., and HIBI, M. (2010). Syntabulin, a motor protein linker, controls dorsa determination. Development 137: 923-933.

NOJIMA, H., SHIMIZU, T., KIM, C. H., YABE, T., BAE, Y. K., MURAOKA, O.,... HIBI, $M$. (2004). Genetic evidence for involvement of maternally derived Wnt canonical signaling in dorsal determination in zebrafish. Mech Dev 121: 371-386.

NOTT, T. J.,PETSALAKI, E., FARBER, P., JERVIS, D., FUSSNER, E., PLOCHOWIETZ, A.,... BALDWIN, A. J. (2015). Phase transition of a disordered nuage protein generates environmentally responsive membraneless organelles. Mol Cell57: 936-947.

ORTEGA, S., PRIETO, I., ODAJIMA, J., MARTIN, A., DUBUS, P., SOTILLO, R.,... BARBACID, M. (2003). Cyclindependent kinase 2 is essential for meiosis but not for mitotic cell division in mice. Nat Genet 35: 25-31.

PAGE, S. L., and HAWLEY, R. S. (2003). Chromosome choreography: the meiotic ballet. Science 301: 785-789.

PAKSA, A., and RAZ, E. (2015). Zebrafish germ cells: motility and guided migration. Curr Opin Cell Biol 36: 80-85.

PENKNER, A. M., FRIDKIN, A., GLOGGNITZER, J., BAUDRIMONT, A., MACHACEK, T., WOGLAR, A., JANTSCH, V. (2009). Meiotic chromosome homology search involves modifications of the nuclear envelope protein MatefinjSUN-1. Cell 139: 920-933.

PEPLING, M. E. (2012). Follicular assembly: mechanisms of action. Reproduction 143: $139-149$ 
PEPLING, M. E., DE CUEVAS, M., and SPRADLING, A. C. (1999). Germline cysts: a conserved phase of germ cell development? Trends Cell Biol 9: 257-262.

PEPLING, M. E., WILHELM, J. E., O'HARA, A. L., GEPHARDT, G. W., and SPRADLING, A. C. (2007). Mouse oocytes within germ cell cysts and primordial follicles contain a Balbiani body. Proc Natl Acad Sci USA 104: 187-192.

PIOTROWSKA, K., and ZERNICKA-GOETZ, M. (2001). Role for sperm in spatial patterning of the early mouse embryo. Nature 409: 517-521.

REITER, J. F., BLACQUE, O. E., and LEROUX, M. R. (2012). The base of the cilium: roles for transition fibres and the transition zone in ciliary formation, maintenance and compartmentalization. EMBO Rep 13: 608-618.

RIEMER, S., BONTEMS, F., KRISHNAKUMAR, P., GOMANN, J., and DOSCH, R. (2015a). A functional Bucky ball-GFP transgene visualizes germ plasm in living zebrafish. Gene Expr Patterns 18: 44-52.

RODLER, D., and SINOWATZ, F. (2013). Expression of intermediate filaments in the Balbiani body and ovarian follicular wall of the Japanese quail (Coturnix japonica). Cells Tissues Organs 197: 298-311.

RODRIGUEZ-MARI, A., CANESTRO, C., BREMILLER, R. A., CATCHEN, J. M., YAN, Y. L., and POSTLETHWAIT, J. H. (2013). Retinoic acid metabolic genes, meiosis, and gonadal sex differentiation in zebrafish. Plos One 8: e73951.

RODRIGUEZ-MARI, A., CANESTRO, C., BREMILLER, R. A., NGUYEN-JOHNSON, A., ASAKAWA, K., KAWAKAMI, K., and POSTLETHWAIT, J. H. (2010). Sex reversal in zebrafish fancl mutants is caused by Tp53mediated germ cell apoptosis. PLoS Genet 6: e1001034.

RODRIGUEZ-MARI, A., YAN, Y. L., BREMILLER, R. A., WILSON, C., CANESTRO, C., and POSTLETHWAIT, J. H. (2005). Characterization and expression pattern of zebrafish Anti-Mullerian hormone (Amh) relative to sox9a, sox9b, and cyp19a1a, during gonad development. Gene Expr Patterns 5: 655-667.

SAITO, K., SAKAI, C., KAWASAKI, T., and SAKAI, N. (2014). Telomere distribution pattern and synapsis initiation during spermatogenesis in zebrafish. Dev Dyn 243: 1448-1456.

SAITO, K., SIEGFRIED, K. R., NUSSLEIN-VOLHARD, C., and SAKAI, N. (2011). Isolation and cytogenetic characterization of zebrafish meiotic prophase I mutants. Dev Dyn 240: 1779-1792.

SATIR, P., and CHRISTENSEN, S. T. (2007). Overview of structure and function of mammalian cilia. Annu Rev Physiol 69: 377-400.

SATO, A., ISAAC, B., PHILLIPS, C. M., RILLO, R., CARLTON, P. M., WYNNE, D. J.,... DERNBURG, A. F. (2009). Cytoskeletal forces span the nuclear envelope to coordinate meiotic chromosome pairing and synapsis. Cell 139: 907-919.

SCHERTHAN, H. (2001). Abouquet makes ends meet. Nat Rev Mol Cell Biol2:621-627.

SELMAN, K., WALLACE, R. A., SARKA, A., and QI, X. P. (1993). Stages of Oocyte Development in the Zebrafish, Brachydanio-Rerio. J. Morphol. 218: 203-224.

SHIBUYA, H., HERNANDEZ-HERNANDEZ, A., MORIMOTO, A., NEGISHI, L., HOOG, C., and WATANABE, Y. (2015). MAJIN Links Telomeric DNA to the Nuclear Membrane by Exchanging Telomere Cap. Cell 163: 1252-1266.

SHIBUYA, H., ISHIGURO, K., and WATANABE, Y. (2014). The TRF1-binding protein TERB1 promotes chromosome movement and telomere rigidity in meiosis. Nat Cell Biol 16: 145-156.

SHIBUYA, H., MORIMOTO, A., and WATANABE, Y. (2014). The dissection of meiotic chromosome movement in mice using an in vivo electroporation technique. PLoS Genet 10: e1004821.

SONG, H. W., CAUFFMAN, K., CHAN, A. P., ZHOU, Y., KING, M. L., ETKIN, L. D., and KLOC, M. (2007). Hermes RNA-binding protein targets RNAs-encoding proteins involved in meiotic maturation, early cleavage, and germline development. Differentiation 75: 519-528.

STARR, D. A., and FRIDOLFSSON, H. N. (2010). Interactions between nuclei and the cytoskeleton are mediated by SUN-KASH nuclear-envelope bridges. Annu Rev Cell Dev Biol 26: 421-444.
TAO, Q., YOKOTA, C., PUCK, H., KOFRON, M., BIRSOY, B., YAN, D.,... HEASMAN, J. (2005). Maternal wnt11 activates the canonical wnt signaling pathway required for axis formation in Xenopus embryos. Cell 120: 857-871.

TOMITA, K., and COOPER, J. P. (2007). The telomere bouquet controls the meiotic spindle. Cell 130: 113-126.

TORETSKY, J. A., and WRIGHT, P. E. (2014). Assemblages: functional units formed by cellular phase separation. J. Cell Biol. 206: 579-588.

TRAN, L. D., HINO, H., QUACH, H., LIM, S., SHINDO, A., MIMORI-KIYOSUE, Y.,... SAMPATH, K. (2012). Dynamic microtubules at the vegetal cortex predict the embryonic axis in zebrafish. Development 139: 3644-3652.

TRELLES-STICKEN, E., ADELFALK, C., LOIDL, J., and SCHERTHAN, H. (2005). Meiotic telomere clustering requires actin for its formation and cohesin for its resolution. J Cell Biol 170: 213-223.

TRELLES-STICKEN, E., DRESSER, M. E., and SCHERTHAN, H. (2000). Meiotic telomere protein $\mathrm{Ndj} 1 \mathrm{p}$ is required for meiosis-specific telomere distribution, bouquet formation and efficient homologue pairing. J Cell Biol 151: 95-106.

TWORZYDLO, W., KISIEL, E., JANKOWSKA, W., WITWICKA, A., and BILINSKI, S. M. (2016). Exclusion of dysfunctional mitochondria from Balbiani body during early oogenesis of Thermobia. Cell Tissue Res. 366: 191. doi:10.1007/s00441. 016-2414-x

TWORZYDLO, W., MAREK, M., KISIEL, E., and BILINSKI, S. M. (2016). Meiosis, Balbiani body and early asymmetry of Thermobia oocyte. Protoplasma 254: 649. doi:10.1007/s00709-016-0978-7

UKESHIMA, A., and FUJIMOTO, T. (1991). A fine morphological study of germ cells in asymmetrically developing right and left ovaries of the chick. AnatRec230:378-386.

VIERA, A., ALSHEIMER, M., GOMEZ, R., BERENGUER, I., ORTEGA, S., SYMONDS, C. E., SUJA, J. A. (2015). CDK2 regulates nuclear envelope protein dynamics and telomere attachment in mouse meiotic prophase. J Cell Sci 128: 88-99.

VIERA, A., RUFAS, J. S., MARTINEZ, I., BARBERO, J. L., ORTEGA, S., and SUJA, J. A. (2009). CDK2 is required for proper homologous pairing, recombination and sex-body formation during male mouse meiosis. J Cell Sci 122: 2149-2159.

WANG, J. T., SMITH, J., CHEN, B. C., SCHMIDT, H., RASOLOSON, D., PAIX, A.,... SEYDOUX, G. (2014a). Regulation of RNA granule dynamics by phosphorylation of serine-rich, intrinsically disordered proteins in C. elegans. Elife 3: e04591.

WANG, J. T., SMITH, J., CHEN, B. C., SCHMIDT, H., RASOLOSON, D., PAIX, A.,... SEYDOUX, G. (2014b). Regulation of RNA granule dynamics by phosphorylation of serine-rich, intrinsically disordered proteins in C. elegans. Elife 3: e04591

WEAKLEY, B. S. (1967). "Balbiani's body" in the oocyte of the golden hamster. $Z$ Zellforsch Mikrosk Anat 83: 583-588.

WICKSTROM, S. A., MASOUMI, K. C., KHOCHBIN, S., FASSLER, R., and MASSOUMI, R. (2010). CYLD negatively regulates cell-cycle progression by inactivating HDAC6 and increasing the levels of acetylated tubulin. EMBO J 29: 131-144.

WILHELM, J. E., BUSZCZAK, M., and SAYLES, S. (2005). Efficient protein trafficking requires trailer hitch, a component of a ribonucleoprotein complex localized to the ER in Drosophila. Dev Cell 9: 675-685.

XIE, T. (2013). Control of germline stem cell self-renewal and differentiation in the Drosophila ovary: concerted actions of niche signals and intrinsic factors. Wiley Interdiscip Rev Dev Biol 2: 261-273.

YAN, W., MA, L., ZILINSKI, C. A., and MATZUK, M. M. (2004). Identification and characterization of evolutionarily conserved pufferfish, zebrafish, and frog orthologs of GASZ. Biol Reprod 70: 1619-1625.

YANG, R., and FELDMAN, J. L. (2015). SPD-2jCEP192 and CDK Are Limiting for Microtubule-Organizing Center Function at the Centrosome. CurrBiol25: 1924-1931.

YOON, C., KAWAKAMI, K., and HOPKINS, N. (1997). Zebrafish vasa homologue RNA is localized to the cleavage planes of 2- and 4-cell-stage embryos and is expressed in the primordial germ cells. Development 124: 3157-3165.

ZHANG, H., ELBAUM-GARFINKLE, S., LANGDON, E. M., TAYLOR, N., OCCHIPINTI, P., BRIDGES, A. A.,... GLADFELTER, A. S. (2015). RNA Controls PolyQ Protein Phase Transitions. Mol Cell 60: 220-230. 


\section{Further Related Reading, published previously in the Int. J. Dev. Biol.}

OCT4 and the acquisition of oocyte developmental competence during folliculogenesis

Maurizio Zuccotti, Valeria Merico, Martina Belli, Francesca Mulas, Lucia Sacchi, Blaz Zupan, Carlo Alberto Redi, Alessandro Prigione, James Adjaye, Riccardo Bellazzi and Silvia Garagna

Int. J. Dev. Biol. (2012) 56: 853-858

http://www.intjdevbiol.com/web/paper/120174mz

Influence of the zona pellucida of the mouse egg on folliculogenesis and fertility

Paul M. Wassarman and Eveline S. Litscher

Int. J. Dev. Biol. (2012) 56: 833-839

http://www.intjdevbiol.com/web/paper/120136pw

In vitro germ cell differentiation during sex differentiation in a teleost fish

Tohru Kobayashi

Int. J. Dev. Biol. (2010) 54: 105-111

http://www.intjdevbiol.com/web/paper/082836tk

Molecular aspects of avian oogenesis and fertilisation

Bozenna Olszanska and Urszula Stepinska

Int. J. Dev. Biol. (2008) 52: 187-194

http://www.intjdevbiol.com/web/paper/072329ob

Follicular cell differentiation in polytrophic ovaries of a moth midge, Tinearia alternata Marta Mazurkiewicz and Janusz Kubrakiewicz

Int. J. Dev. Biol. (2008) 52: 267-278

http://www.intjdevbiol.com/web/paper/072318mm

Accessory nuclei in insect oogenesis: in search of the function of enigmatic organelles Mariusz K. Jaglarz, Malgorzata Kloc and Szczepan M. Bilinski Int. J. Dev. Biol. (2008) 52: 179-185

http://www.intjdevbiol.com/web/paper/072303mj

Formation of polar cytoplasmic domains (teloplasms) in the leech egg is a three-step segregation process

J Fernandez, N Olea, A Ubilla and V Cantillana

Int. J. Dev. Biol. (1998) 42: 149-162

http://www.intjdevbiol.com/web/paper/9551860
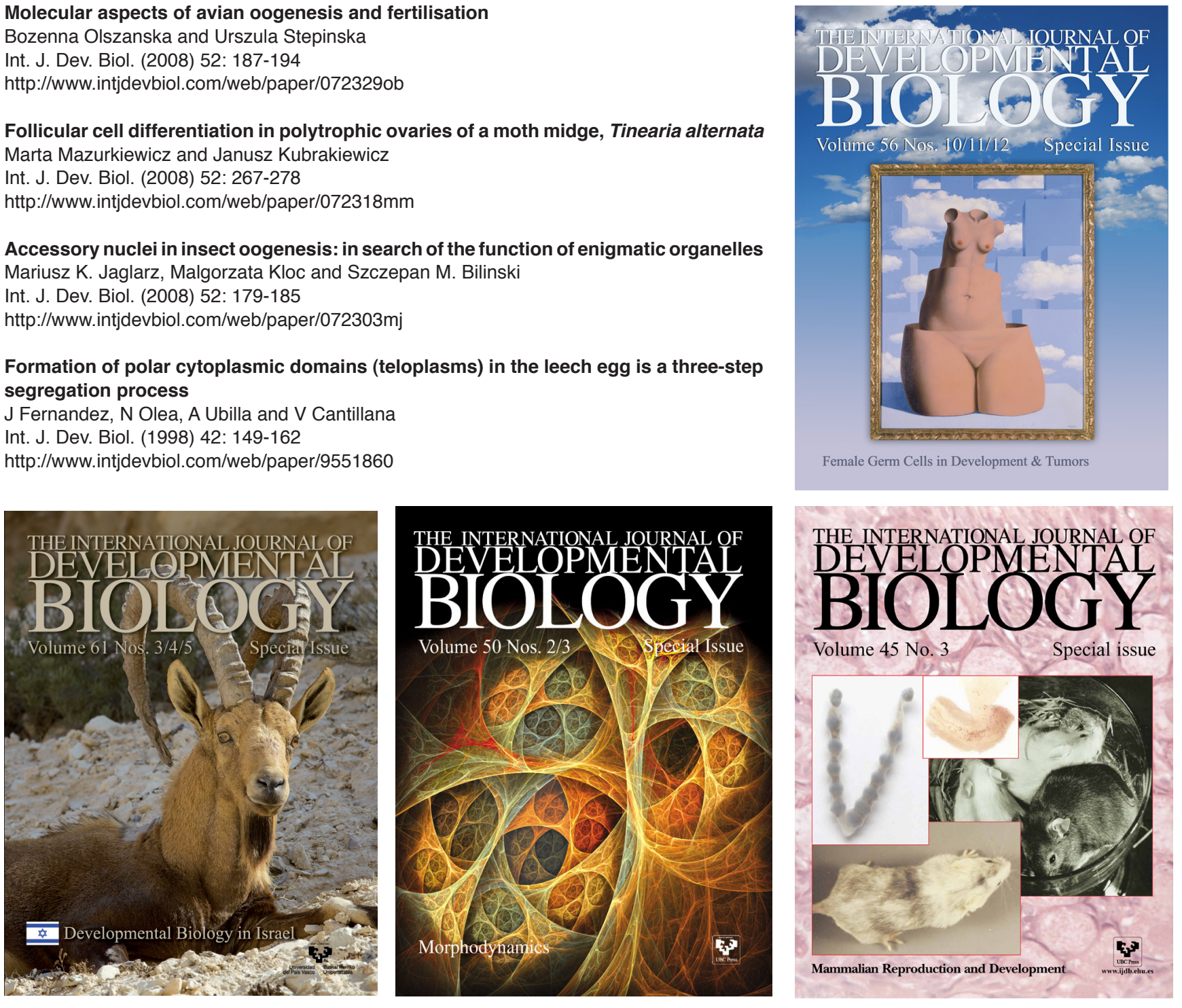